\title{
Determine Sinkholes and Overburden Thicknesses in Selected Covered Carbonate Karst Terrains (Kinta Valley), Perak, Malaysia by Combining Wenner E.R. Tomography, Geological and Satellite Images Techniques
}

\author{
Riyadh R. Yassin ${ }^{1}$, Ros Fatihah Muhammad ${ }^{1}$ \& Samsudin Hj Taib ${ }^{1}$ \\ ${ }^{1}$ Department of Geology, Faculty of Science, University of Malaya, 50603 Kuala Lumpur, Malaysia \\ Correspondence: Riyadh R. Yassin, Department of Geology, Faculty of Science, University of Malaya, 50603 \\ Kuala Lumpur, Malaysia. E-mail: riyadh.geophsea@gmail.com
}

Received: May 21, 2014 Accepted: June 17, 2014 Online Published: November 28, 2014

doi:10.5539/jgg.v6n4p199 ～URL: http://dx.doi.org/10.5539/jgg.v6n4p199

\begin{abstract}
This paper discusses the application of Wenner's Electrical Resistivity Tomography, geological, and satellite-imaging techniques to the process of determining sinkholes and overburdened thickness in covered carbonate karst terrains. The study area is located in (Kinta Valley), at a place called Kampung Kunsila estate, situated northwest of Kampar City and south of Ipoh, the capital of Perak, Peninsular Malaysia.
\end{abstract}

Several active sinkholes were discovered and identified during site field inspections. The sinkholes ranged from narrow-to-medium and medium-to-wide sizes, some with exposed throats. On average, the diameter of the sinkholes in the study area ranged from $1 \mathrm{~m}$ to more than $\sim 30 \mathrm{~m}$, some having approximately the corresponding range in depth. Surface water induces erosion along the frame of the sinkhole, which causes enlargement to several meters long. Some of the sinkholes were selected for the application of high-resolution geophysical technique in order to realize the objectives of the study.

Wenner's Electrical Resistivity Tomography (ERT) was used along many profiles to capture the image of the subsurface across and in proximity to various types of sinkholes as a primary stage. This method will allow the recognition of their shapes and estimation of their depths. In addition it will assist to know the origin of these sinkholes.

The resistivity data from the multi-electrode measurements were collected at several profiles were plotted in graphs/maps. The resistivity maps showed images of many active karstic cavities and sinkholes having different shapes and origins. Some of these were identified as karstic features (sinkholes and cavities) as well water, clay or air infill. Additionally, the transmission of the material from the top (soil surface) down to the bedrocks via the solution showed enlarged joints, drainage systems or pipes, which is expected.

The interpretation of the resistivity data was used to generate a geological model of the specified area. The geological model derived from the interpretation of the geophysical data consisted of a basal limestone unit, which was widely karstified and constituted the bedrock of the study area. The overburdened layers consist of sand, containing lenses of clay and covered by soil or sandy clay and friable sand. There are also rock fragments scattered throughout. This karstified limestone bedrock is intervened with sinkholes and cavities, in-filled with clay or sandy clay and sand. This is invariably interpreted as a karstic process.

A certain variety of sinkholes with differing origins was identified in the study area via the information from the geological and geophysical survey data records. The first type of identified sinkholes was a few meters in diameter and depth and was referred to as cover-layers or material subsidence. The second type was wider than the first type in terms of diameter and depth, referred to as cover-collapse sinkholes; and the third kind of sinkhole is a slump depression produced on the ground surface. Finally, the fourth type is an opening with a funnel shape depression or sink, referred to as pipes.

The field study identified the type of sediments in the subsurface's layers, and estimated its approximate depth and thickness. Moreover, the depth of the limestone bedrock was generated for all sites. The tomography data from different profiles were interpreted using the existence of the extracted boring samples to improve the results 
of the ERT. When comparing the interpretations from individual profiles with the boring data, a discrepancy is detected in the depth values, speculated to be resulting from variations between the normal subsurface geology and the data from the electrical resistivity survey profiles. Most of the data points contain errors of less than $1 \mathrm{~m}$, with some data points containing errors of less than $3 \mathrm{~m}$.

This study also discovered that this area and other areas with similar specifications are hazardous vis-à-vis constructing accommodation for habitation or animal sheds. There is a possibility of collapse or subsidence of the soil cover or the material and underlying layers due to the load at any time in the near future. This study also identified an area of ongoing subsurface dissolutional erosion that may eventually lead to a collapse in the future. Two solution methods are recommended to use in the plan to minimize the risk of problem areas in this site.

Keywords: sinkholes, overburden thicknesses, carbonate karsts, combining techniques, Perak-Peninsular Malaysia

\section{Introduction}

Karst in carbonate terrains is a distinctive landscape and hydrology, which occurs from a mixture of high-rock solubility and a well-developed secondary porosity. The carbonate rocks (limestone, dolomite, marble) are often characterized by a group of landforms, which includes an extensive range of closed surface depressions, underground drainage, well-developed systems, and sinkholes. These depressions form the main focus of this paper.

Sinkholes appear due to many reasons, such as being the result of the runoff of heavy rains channeled towards the bedrock from the flow of groundwater; irregular distribution of unconsolidated material over the bedrock surface; or subsidence movement. Many carbonate rocks contain various amounts of insoluble materials and solution-enlarged joints. When the soluble components are dissolved and removed by groundwater, the insoluble materials remain, which include sedimentary material such as gravel, sand, silt and clay. Sediments such as alluvial or marine sediments may also mantle the bedrock. Regardless of their purported origin, the sediments protect the limestone bedrock and prevent any solution-related features in/on it.

Due to the elevation of the limestone/soil interface being location dependent, defining the depth to the carbonate bedrock with the boring data is time-uncontrollable and expensive, and may be misleading due to insufficient data density. On the other hand, the boundary between rock and soil is often sharply defined Sowers, G.F. (1996). The overburdened soil differs from the underlying carbonate rock, whether it is residual soils produced by mechanical and chemical breakdown of rocks from the ground surface, or it is transported from its origin. This contrast provides the basis for applying geophysical techniques to represent sinkholes, the carbonate bedrocks, and the overburdened soil surface in covered karst terrains.

Two-dimensional (2D) electrical resistivity profiles were applied in the proximity of active and non-active sinkholes at the Kunsila estate site, situated in northwest of Kampar and south of Ipoh, as shown in Figure 1. Forty-one steel electrode arrays were employed in these surveys, with a spacing of $5 \mathrm{~m}$. The length of the electrical survey lines is $200 \mathrm{~m}$, and it depends on the size of area and the placement of the wire arrays. The space between the two lines was on average $10 \mathrm{~m}$ at this site.

The electrical resistivity data acquired from the survey is constructive for several reasons, among them the fact that karstic features can be delineated by a completed closely spaced parallel resistivity profile; and the subsurface can be immediately imaged across and in proximity to many sinkholes in order to determine the karstic features. The provided images were reliable, and support the interpretation about the study area, if it is underlain by several varieties of karst features (sinkholes, cavities and voids). The survey shows sinkholes, in many different sizes and shapes can be recognized in the study area. It is capable of characterizing the subsurface bedrock in covered karst terrains.

In this study, it is recognized that the subsurface limestone bedrock was widely karstified by providing reliable images of the karstified limestone bedrock. On top of identifying the type of sediments in the subsurface layering, which includes estimating its approximate depth and thickness, it also indicated that the surface was overlaid in various places by friable sand and the remnants of limestone rock and other rock fragments. This is due to the high resistivity recorded in most of the overburdened cover. Furthermore, it also allows an understanding and prediction of whether or not an area in the vicinity to this study area might be a threat in the near future. 


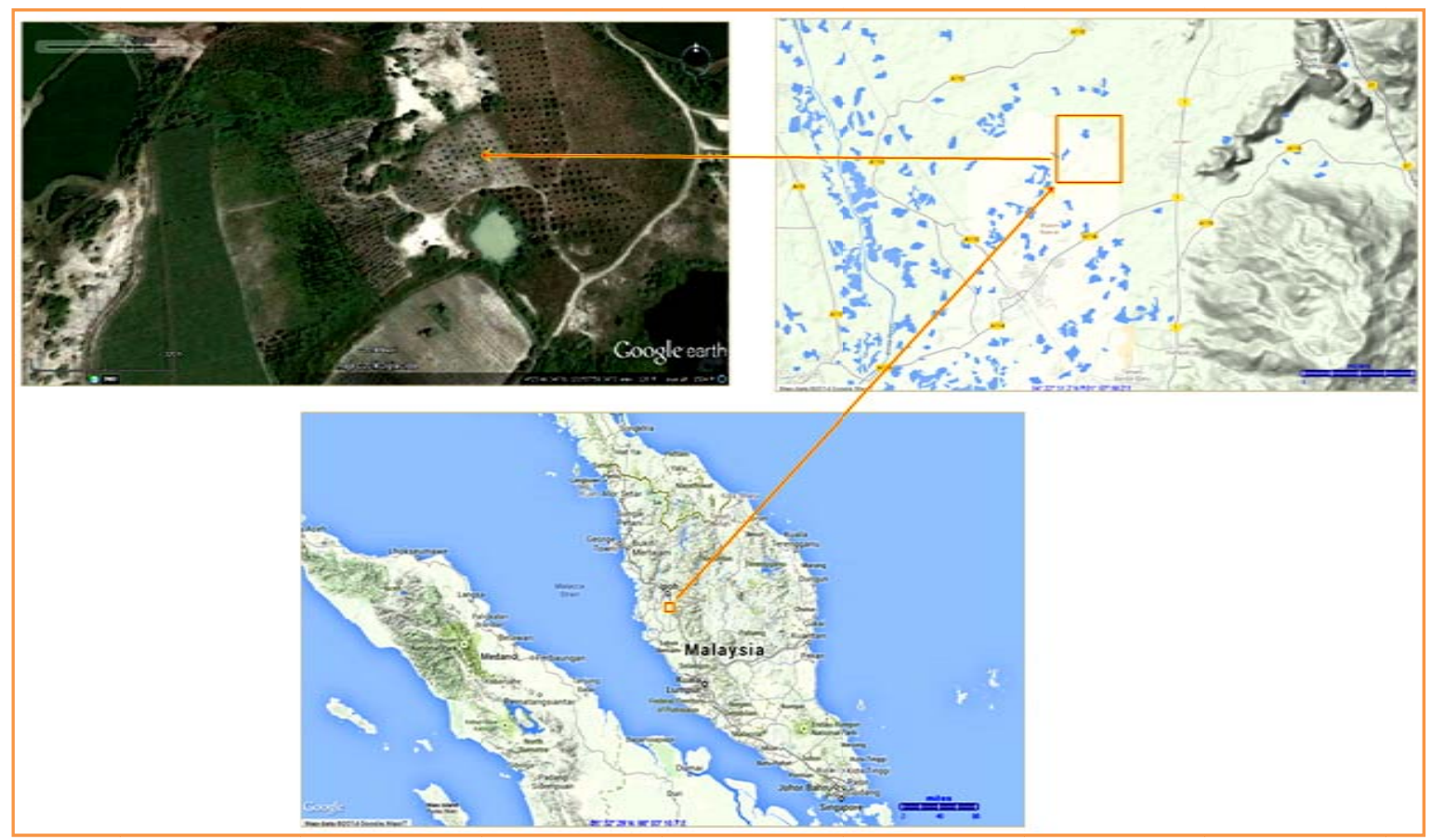

Figure 1. Google Normal, terrain, Satellite image viewing the location of the study area in (Kinta Valley) northwest of Kampar City and south of Ipoh, the capital of Perak, Peninsular Malaysia

This study also discusses many considerations about the important elements which play major roles in the development of karst phenomena and the dissolution process which effect in the increasing of carbonate karst features in the Sungai Perak Basin (Kinta Valley).

\section{Objective of Study}

The geophysical investigations method (ERT) was conducted at fundamental sites in order to determine the following objectives:

Imaging the subsurface immediately across and in proximity to many sinkholes and determine other karstic features such as voids, cavities.

Estimate the depth of these sinkholes.

Recognize the shape of the sinkholes.

Understand the origin of these sinkholes.

Determine the type of sediments and the subsurface layering, including its depth and thickness.

Generate a geological model of the study area.

Pinpoint air-filled karstic voids or cavities present in the subsurface.

Understand if approximating this study area will create any probable threat in the future.

\section{Location of the Study Area}

The study area is located in (Kinta Valley), at a place called Kampung Kunsila estate, east of Kledang series, as shown in figure 2, with GPS coordinates of latitude $\mathrm{N} 4^{\circ} 23^{\prime} 44.16^{\prime \prime}-\mathrm{N} 4^{\circ} 23^{\prime} 56.88^{\prime \prime}$ and longitude E101 ${ }^{\circ} 07^{\prime}$ 52.46" - E101 08' 6.78". It is situated northwest of Kampar and south of Ipoh, the capital of Perak, Peninsula Malaysia. Figure 2 viewing the location of the study area in land use map, satellite image, and land-photographs. 


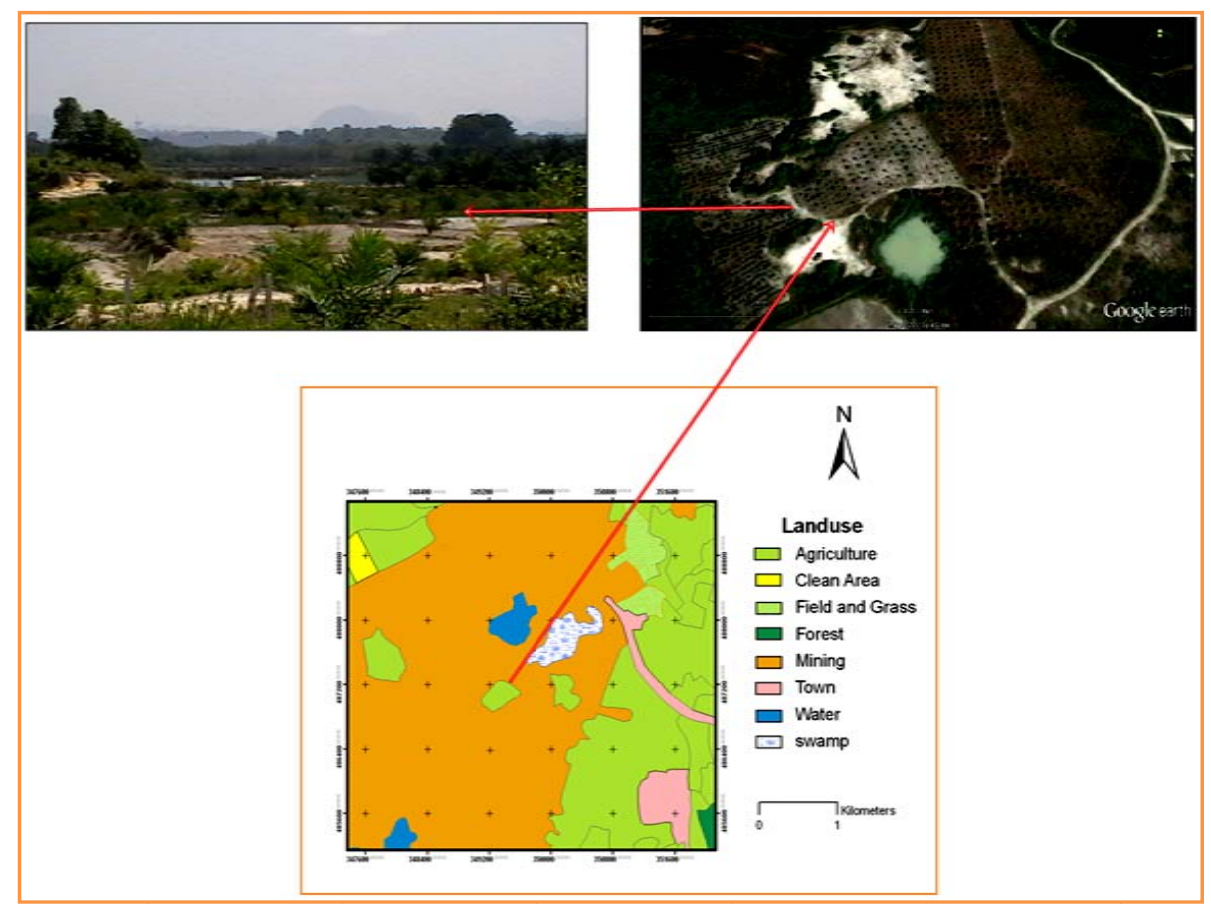

Figure 2. Land use map, satellite image, land photograph viewing the study area located in Kunsila estate, North West of Kampar City and south of Ipoh City the capital of Perak state

\section{Geology of the Study Area}

Kinta Valley, located in western Peninsular Malaysia, forms a V-shaped valley open to the south and bounded by the granitic massif of the Main Range to the east and of the Western or Kledang Range to the west. The granite that forms the mountains have been dated to the Triassic age Cobbing, E.J. et al. (1992).

The limestone hills are the remnants of extensive limestone beds, which are part of large Palaeozoic carbonate platform complexes that covered parts of Southeast Asia. Palaeozoic limestone outcrops area scattered intermittently throughout Peninsula Malaysia. The original limestone beds of the Kinta Valley, presumed to be Carboniferous, Ingham, F.T., \&Bradford, E.P. (1960); Hutchinson, C.S. (2007) or possibly Permian in age Fontaine, H., bin Amnan, I. (1995), have been severely eroded and karstified.

Deposited more than 250 million years ago and buried to great depths, lithified and eventually brought to the surface by tectonic forces, presumably in the Mesozoic, the Palaeozoic limestone of the Kinta Valley was exposed to a humid tropical to equatorial climate for very long periods of time, which slowly dissolves the limestones. The hills are the only remaining visible part of the Palaeozoic limestone layers underlying the tertiary to recent alluvial deposits over the entire expanse of the Kinta Valley and beyond.

The limestone of Kinta Valley overlies extensive younger granite bodies, which affects the texture and composition of the limestone via contact metamorphism at the time of granite intrusion. This has been dated as originated from the Triassic age Cobbing, E.J. et al. (1992). Initial observations reveal that the degree of metamorphism of the limestone varies from hill to hill, from low (practically intact limestone) to high (limestone entirely turned to marble). Most of the Kinta Valley limestone has undergone contact metamorphism from Sungei Siput in the north to Tapah in the south. The less metamorphosed limestone is located in the northern part of Kinta Valley. Figure 3, present the location of the study area on the satellite image of Kinta Valley, Perak. 


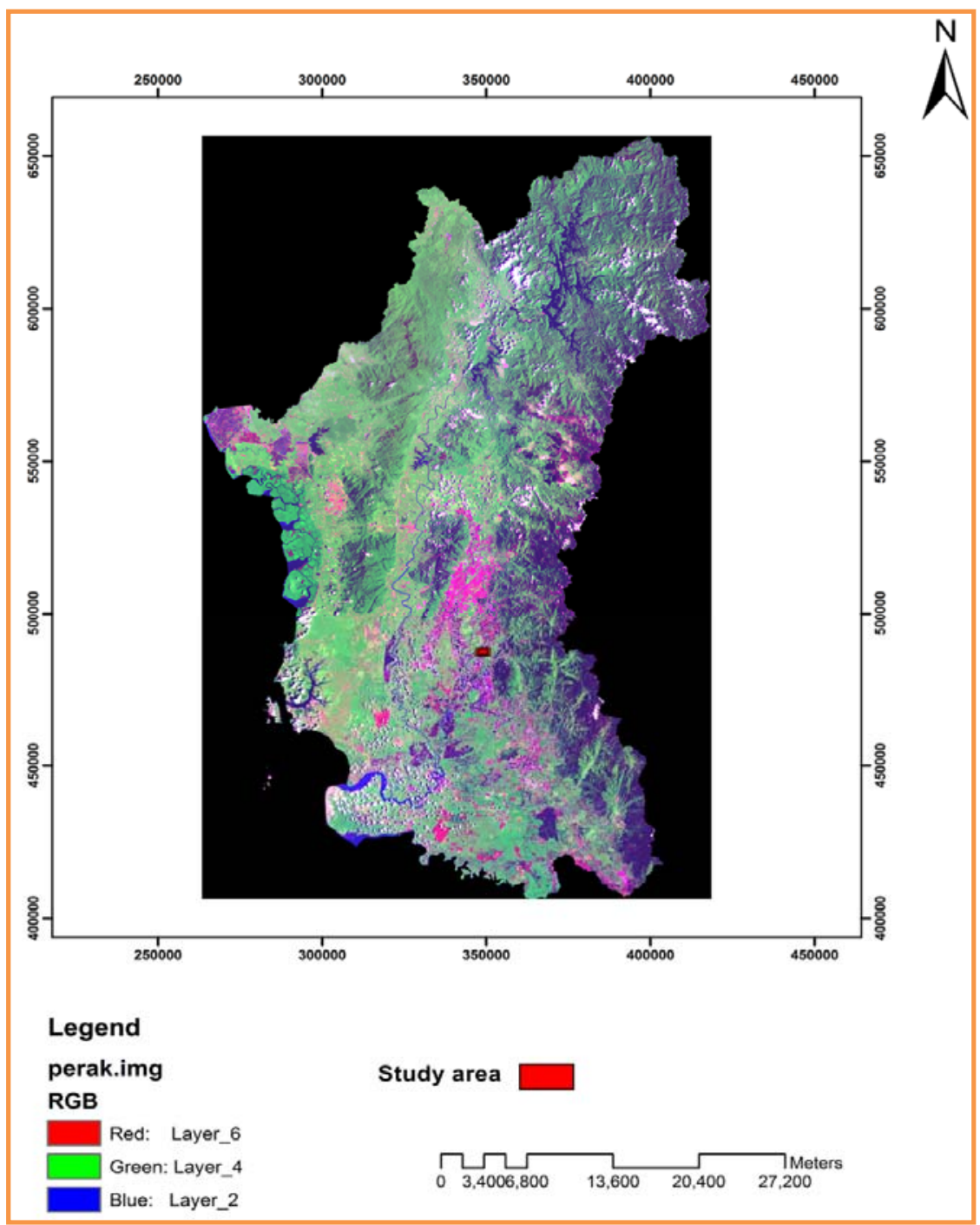

Figure 3. Satellite image of Kinta valley, Perak, present the location of the study area

\subsection{Carbonate Karst Terrains}

Karst in carbonate terrains is a type of landscape found on carbonate rocks (limestone, dolomite, marble), and is characterized by a group of landforms, including an extensive range of closed surface depressions, underground drainage well-developed system, and a lack of surface streams Cooper, A. H. et al. (2011). Limestone or dolomite carbonate karst terrains are generally active and diverse in character, and exhibit low solubility, high mechanical strength and in some cases, low ductility. The dissolution process happens very slowly; a few millimeters may be dissolved within a hundred years, which has the potential to create a cavity of $1 \mathrm{~m}$ or more across in more than a hundred years. Its highly irregular depths of bedrock, residual red clay-rich soil, and surface drainages usually characterize the carbonate karst terrains, which fade away in the underground.

Karst develops on soluble rocks, both at the surface and subsurface, due to the rate of dissolution processes that work in rapidly developing limestone rocks. This depends on a number of factors, such as the power of rainfall, availability of surface water, and its form to revive as well as groundwater. Other factors include the distribution of soil-cover, temperature and biological activity, diffusion rate, autogenic content, structural weakness and lithology of the carbonate sub-layers.

Most sinkholes in carbonate karst rocks are formed via the dissolution processes with acidic water, which occurs when rainwater absorbs carbon dioxide from the air and decomposing organic material in the soil. It becomes more acidic, and penetrates into the cracks, which dissolves the rocks. Carbonate karst can be a part of the global carbon cycle, in which carbon is exchanged between the atmosphere, surface and underground water and 
carbonate minerals. The dissolution of carbonates via the presence of acid in water combines the carbon derived from the rock and from dissolved $\mathrm{CO} 2$ as aqueous HCO3.

The deposition of dissolved carbonate minerals is accompanied, and usually generated by the release of some of the carbon as CO2.When the bedrock is water-saturated, the dissolution continues along the bedding planes through the horizontal cracks between rock layers and joints, or fractures in the rock itself. These conduits enlarge over time, and the water moving through the combination of gravity and hydraulic pressure and it will further enlarge the conduits via a combination of dissolution and abrasion of the surrounding rocks. The communication varieties among chemical, physical and biological processes have a broad range of geological effects, including dissolution, precipitation, and sedimentation and ground subsidence. Diagnostic features such as sinkholes (dolines), sinking streams, caves and large springs are the result of the dissolutional action of circulating groundwater, which may be dispersed to entrenched effluent streams.

Initially, most of the underground water moves by laminar flow within narrow fissures, which gradually become enlarged at or below the water table to form subsurface caves. Once a certain conduit-size threshold is exceeded, which is typically around 10 to 20 millimeters, the flow becomes turbulent. The caves contain a variety of dissolution features, sediments and speleothems (deposits with various forms and mineralogy, chiefly calcite), all of which may preserve a record of the geological and climatic history of the area, surface and subsurface, due to the solution and associated processes.

Most sinkholes were created on soluble carbonate rocks (marble, limestone and dolomite) because of greater dissolution related with the difference in composition. The sinkholes developed at both the surface and subsurface are due to the solution and associated processes. Yassin, R.R. (2002) has documented three main and most imperative situations that may lead to development of sinkholes in karst region under tropical climate:

Firstly, due to discrepancy of dissolution in areas, the power of rainwater is greatest at the surface and the first 10 $\mathrm{m}$ from it; so the surface of exposed or uncovered carbonate outcrops has eroded, thus lowering the ground in the area. This generally results in sinkholes with shallow depression that may extend up to several tenths of meters. The materials then move away within slowly enlarging fissures, whereby initial openings and cracks are produced by the continuation of the dissolving process on the soluble rocks. This is due to activity of the depressive waters. An internal karst conduit system into the underlying carbonate occurs and results in the growth of cavities in the rock. If the ceiling or the upper limit of the cavity is not strong and eventually collapses, a sinkhole may form at the ground surface.

Secondly, in the subsurface, dissolution and downward gravitational movement of the overlying material due to deformation and internal erosion occurs. Rainwater with a high amount of carbon dioxide finds its way through the cracks and causes fractures in the underlying porous limestones rocks, which converts the calcium carbonate by a chemical process into dissolved bicarbonate. The dissolved substance is then washed away. Consequently, the original minute-line cracks or the joints in the rock are gradually widened and enlarged; hence, it produces a pattern of fissures. If rainwater penetrates deeper into the subsurface, it forms cavities by corrosion.

When this rainwater starts to flow through the underground cavities, it accumulates and fills the holes. Due to the mechanical process of erosion, a destructive action in breaking down and carrying away the rock in a system of linked cavities, cracks and channels. The water can build up pressure, forming dams that can occasionally cause water to flow uphill. Watercourses can develop consisting of caverns, passages and channels or conduits and the faster the water flows the deeper the underground cavern becomes completely filled with water. The dissolution process then depends on the rate at which the water percolates or seep into cavern through the roof. If the land above the cavern is covered with forests, the flow of water with high carbon dioxide content will be much stronger than on under grazing land or a totally exposed surface. Collapse of the cavity roofs caused by dissolution over voids (by the upward diffusion) also results. Deep-seated dissolutional voids may be associated with this phenomenon. Also, a pipe that may reach several hundred meters in height and with sharp-edged depressions up to a few tens of meters in diameter generally results.

Thirdly, the situation caused by tectonic activity and earthquakes in karst terrain regions plays a major role in development of sinkholes in both surface and subsurface. Tectonic fractures occur and these enlarge the networks of open fissures. Collapse or subsidence of the ground surface occurs as the soil slumps, widening both joints and fractures. Constructive flow paths enlarge selectively into caves. The enlargement of a cave or caves and the cavity produced on bedding planes, opening or interconnecting of voids in a block of karstic limestone, may also occur. 


\subsection{Development of the Karst Phenomenon in Kinta Valley}

There are a numbers of important elements which play major roles in development of the karst phenomenon in the Sungai Perak Basin (Kinta Valley). These elements were working together under several conditions in the geologic past. The karst in the Sungai Perak Basin has developed under the following conditions:

- Tectonic condition through the past period.

- Varying of climate conditions through the past period from humid tropical to seasonal savanna and arid seasonal.

- Constant conditions of water supply from rainfall in most seasons.

- The conditions of flood plain in Kinta valley form an area of active fluvial activities with the availability of large amounts of allogenic water passing through the limestone karst.

The limestone of Kinta valley was affected by intense fracturing. Several lineaments were recorded, and their main orientation appears to be in the NNW-SSE as shown in Google terrains map, figure 4. Several geologists have suggested that major karstification is controlled by the structures in the areas when it's occurred. The structural Geology in the limestone of Kinta valley area are dominated by faults and folds oriented NNW-SSE which gives a noticeable grains to the landscape especially to the orientation of isolated, steep-sided, residual hills (mogotes). Which are composed of either limestone, marble, marblized limestone or dolomite and surrounded by nearly flat alluvial plains in the central part of the valley.

Vertical and sub vertical joints and faults in the marbleized limestone provide the main lines of weaknesses. The subsurface karst is characterized by the formation of rounded top pinnacles and irregularly-shaped sinkholes which had previously referred to as dolines. One of important aspect on the sub-surface karst in the study area particularly in Kinta valley is the presence of one or more concordant levels of the rounded top pinnacles that had been referred to as plat forming levels.

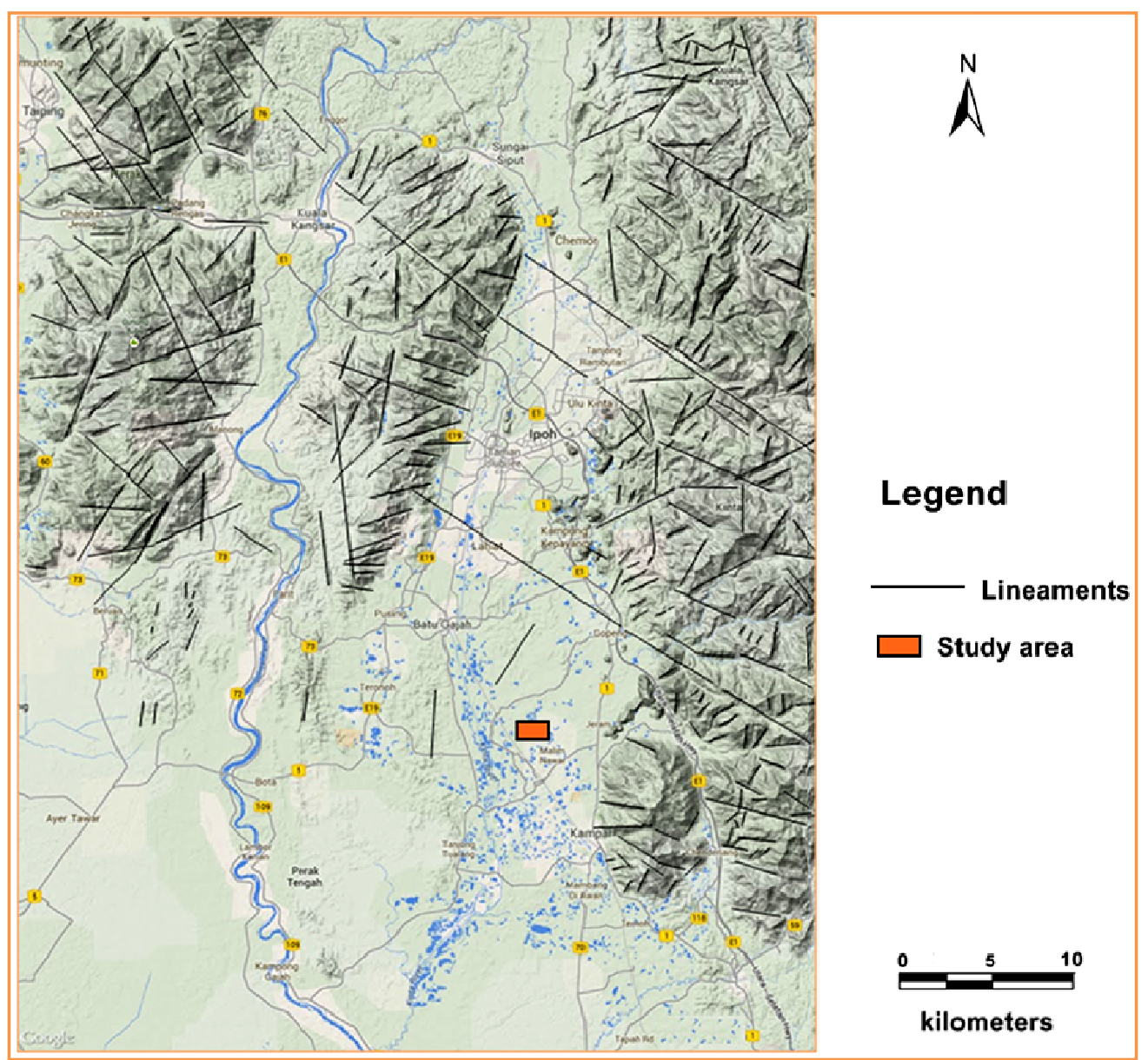

Figure 4. Google terrains map shown several lineaments were recorded with main orientations appears to be in the NNW-SSE 
It is believed that the sub-surface karst is developed below a cover of alluvial sediments during the geologic past Yeap (1998); Dian (1996). The opinions that, the early stage of pinnacle development is due to the differential resistance of physical weathering of the rocks and the role of geological structures (bedding planes, joints, fault etc.) lead to the formation of pinnacles under the cold climates of Tibet to developed. The depth of limestone with few meters from the ground surface can be identified from the depth of pinnacles which determined in ex-mines and sinkholes that distributed in the study area, figure 5 .

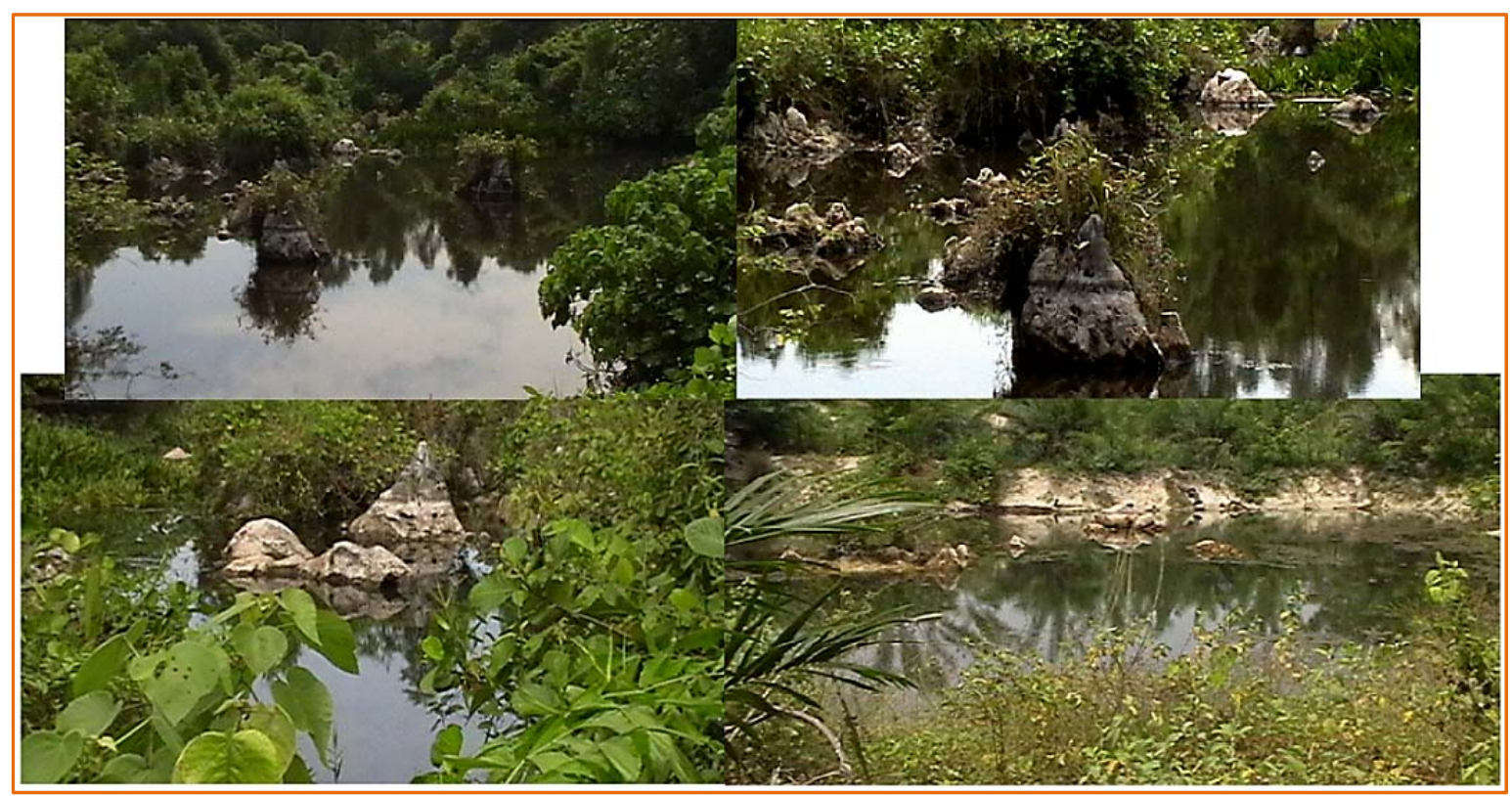

Figure 5. Pinnacles identified in ex-mines and sinkholes that distributed in the study area presenting that the depth of limestone with few meters from the ground surface

The authors researched many studies on the acidity of the rain water done in last fourteen years. The most imperative conclusion drawn is that the enhanced rainfall and elevated acidity of rain water in the last few decades of the 20th and 21st centuries in Malaysia and other countries in Southeast Asia are due to increase amounts of liquefied carbon dioxide and other pollutions. The air pollutant index (API) levels recorded a reading ranging between (112 to 300) in the sky from various states in Malaysia peninsular. The API reading between 0 and 50 is considered good, 51 to 100 is measured (moderate), 101 to 200 (unhealthy), 201 to 300 (very unhealthy), and 301 and above (hazardous).

These are the consequence of volcanic and tectonic activity in the Pacific fire ring, the volcanoes in the Philippines such as Bulusan and Mayon volcanoes in the south east of Manila. In Indonesia such as the Kelud volcano located in East Java, Mount Sinabung volcano in North Sumatra, Mount Merapi volcano located on the border between Central Java and Yogyakarta, Indonesia, being the most active. A spectacular sub-marine volcanic eruption spews out huge columns of ash, smoke, gas and vapors thousands of feet into the Pacific Ocean sky. Liquefied carbon dioxide is also due to land clearing activities such as the burning of large jungle and forest areas those practiced by farmer in Indonesia on a large scale also results in the emission of large volumes of smoke and haze pollutants into the atmosphere. Exhaust emissions from vehicles and waste emissions from factories significantly contribute to air pollution as well. All these events have a large impact on the development and quick dissolving process of carbonate rocks.

The authors also believe that most of the biggest cave and channels in the marbleized limestone of Kinta valley is due to reaction of sulfuric acid (H2SO4) with carbonate rocks this can also be one of the corrosion factors in karst formation, this mechanism may also play a role, as O2-rich surface waters seep into the ground, its brings oxygen which reacts with sulfide present with Cassiterite into the ground surface of Kinta valley area, the oxidation of sulfide leading to the formation of sulfuric acid. Sulfuric acid then reacts with calcium carbonate causing increased erosion within the limestone formation.

The cover layers of alluvial deposits over marbleized limestone of Kinta valley contains soil-piping or channels feature. The Tin (Cassiterite) was accumulated in this alluvial channels or pipes having been washed down from 
the granite ranges and carried by rivers as mentioned previously, which contain sulphur in its chemical deposits have a large impact on the development and quick dissolving process of carbonate rocks.

The satellite images shows that numerous of limestone hills exposed over the valley which effected by dissolution process of the water within geological time. Two groups of tower karst define depending on the complexity of their forms which are composed of either limestone, marble, marblized limestone or dolomite and surrounded by nearly flat alluvial plains in the central part of the valley. The cockpit towers or isolated tower with the steep-sided walls are separated from other hills and contain a single peak represent the remnants of much larger hills that had dissolved away by mainly meteoric water which percolates vertically or subs vertically through the joints or faults. The steep slopes in the tower and cockpit in the tropics are formed due to collapse of the walls. The other type is complex tower which consists of one group of hills with a few peaks and is partially separated from one another by sinkhole.

A further type is the Cone - shape capped by steep-sloped tops of carbonate rocks with gentle slopes from almost the top of the hill to the bottom. The cockpit towers and isolated towers, the complex and cone - shape tower with the steep-sided walls in the study area was presented in figure 6 .

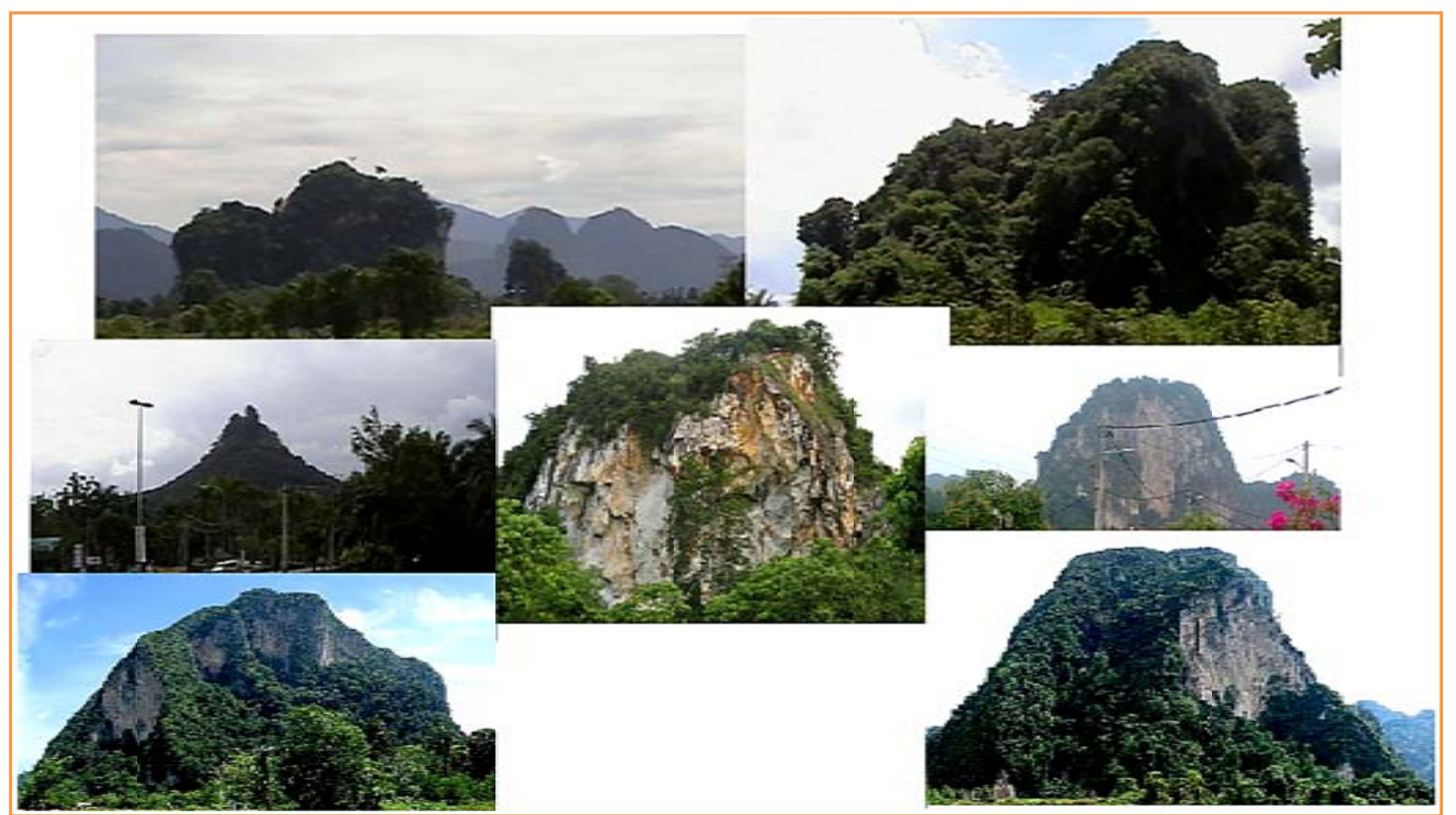

Figure 6. The cockpit towers and isolated towers, the complex and cone - shape tower, hills which are composed of either limestone, marble, marblized limestone or dolomite and surrounded by nearly flat alluvial plains in the central part of the valley

The authors thought that this basin mostly filling with water till mid division -Holocene era (the period that follows the last glacier period) around 11,500 years BP. was probably a result of predictable changes in the Earth's orbit that provided more solar radiation to the Northern Hemisphere, tending to cause greater heating at that time and caused the end of the last glacial period due to a sudden warming of the climate which includes a relatively rapid melting of the ice sheets.

In the early division of Holocene era ice sheets melt caused to a sudden rise to world sea levels led of sea level induced flood leading to a certain extent catastrophe. Sea levels have risen considerably submersing a large portion of the seashores including much of Malaya lands. However, ice melt caused world sea levels to a rise in the early division of the Holocene era and continued to rise till mid division between 6000 years BP till 4000 years BP through that submerging Sunda Shelf, low coastal plains and deltas resembling the Chao Phraya delta in Thailand. Furthermore, submerges the Mekong delta in Vietnam, Sathiamurthy, E.; Voris, H. K. (2006). Then afterward between 4000 years BP to 3500 years BP the sea level become $5 \mathrm{~m}$ high from the present day causes huge disturbances to the seas and tidal waves that run onto the land. Baumgrander, J, (1990a: 1990b; 1994); Austin, et.al. (1994) proposed that due to increase in sea water level, all the original lithosphere became subducted; the rising magma from the hot spate will raise the ocean floor. Due to El Nino cycle which connects 
to a spate of undersea quakes and lava eruptions as reported by Walker, D. A. (1994), has proposed a connection between underwater earthquakes and the incidence of El Ninos. If the volcanic heat were to reach the ocean surface, this would warm the air surrounding it and could generate an El Nino Southern Oscillation (ENSO) event. Scientists reported now a day that the effect of lava eruptions and a spate of undersea quakes had leaded to the start of El Nino cycle. The seismic activity was the most unusual it had been in 30 years and apprehensively linked it to El Nino.

Some of understudies' records of the past climate variability across the tropical Pacific Ocean , due the changes in sea surface temperature (SST) and due to the expose changes in the frequency and intensity of individual El Niño events through time, Shulmeister and Lees (1995); McCulloch, et al. (1996); Gagan, et al. (1998); Fontugne, et al. (1999); Sandweiss et al. (2001); Tudhope et al. (2001); Andrus et al. (2002); Koutavas et al. (2002); Moy et al. (2002); Riedinger, et al., (2002); Cole,(2003); Loubere, et al.(2003); Stott, et al. (2004); Carre, et al. (2005);Rein, et al. (2005); Lea, et al. (2006), there studies indicate that the frequency and intensity of ENSO have varied through the Holocene. The majority of these records suggest that ENSO frequency there was a significantly reduced during the early to mid-Holocene, and there was an increased in frequency for a while in the last few thousand years of Holocene.

The authors believe in the age of 3500-3000 years BP is due to a weakness zone in the area of Pacific ring and due to increase in sea water level that push down the lithosphere (ocean floor) and began sinking over the underlying mantle, due to high pressure and it will squeeze the mantle which lead to the rising up of magma from all the hot spate and cover the entire ocean floor, thus it will grow and rise up and also causing the sea water levels to increase. The emancipation of heat from magma is enough to boiling off all the water of pacific ocean and cause water vapors, enough to produce more than few months of rains. That was the response to heavy rainfall in mid-Holocene round the world in the age about 3500-3000 years BP and led then to global flood (Noah's Flood). The flood water led to sea level will get higher again and hit Malaya land and covers all Kedah land and Kinta valley area. Due to heavy rains which have deeply eroded and washed both highest mountains of granite ranges and the high lands around the Kinta valley and forming new canyons and rivers.

After the volcanic activity stopped, there would be a transition period, the magma was cooled down, the ocean floor lowered again, and the Flood waters receded. The climatic activity decreased and lesser affected the areas of the extreme north and south continents, so after that it would return to frigid climates. With greatly increased moisture in the atmosphere it is theorized that a second ice age as a result.

It is clear that the top soil is wetter soil corresponds to a higher rainfall in mid- Holocene. This type of soil was washed due to the running off heavy rain and drain into the features (fractures, sinkholes and cavities) in the lower layer of sand and can estimate an consideration that these features was formed due to the heavy rains in mid- Holocene, this was determine in electric resistivity tomography sections of geophysical survey in Kinta valley by Yassin R R (2009; 2012) in most of the sites under survey and determine that most of the soil found drained into the features under the covering layer. The authors believe that these features were difficult to proceed in Tertiary because of Miocene uplift tectonic movement and thick Tertiary limestone plateau which overlie by the sandstone.

The cover layer of Soil clay with thickness between $(1.0 \mathrm{~m}-1.25 \mathrm{~m})$ containing different size of granite rocks and minerals are mostly from $(0.5 \mathrm{~cm}-1.0 \mathrm{~cm})$. This appearance is due to runoff of heavy rains which has deeply eroded and washed both highest granite ranges around the Kinta valley and then carried away by the new rivers and canyons which was formed due to the erosion. Soil clay containing different size of granite rocks and minerals found covering different sites in Kinta valley presents in figure 7.

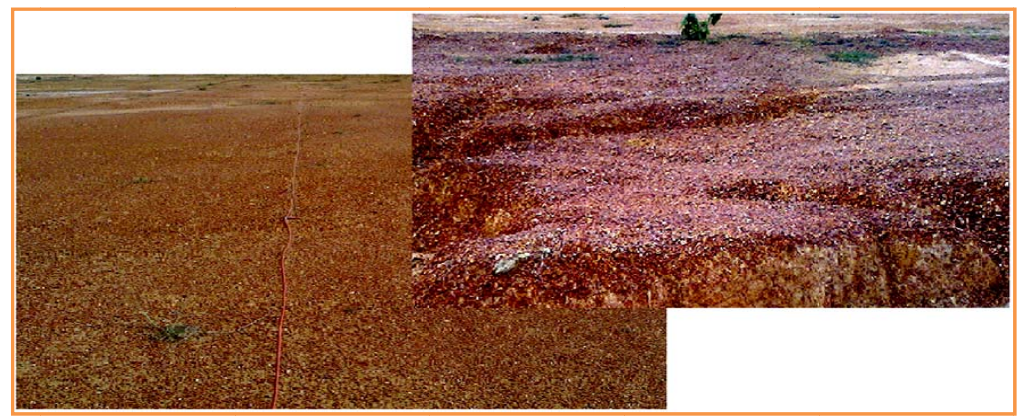

Figure 7. Soil clay containing different size of granite rocks and minerals found covering different sites in Kinta valley 
Some time, runoff and erosion continues; and the sea bed slowly settling down. The pressures of the additional water cause Earthquakes and movements of the surface and sea bottoms resulting in both sinking and rising of land surfaces. Mostly this movement hit Malaya basin in the direction of west - east and south west - north east as shown in the figure, which found little lineaments in this direction, leading the water to escapes through the faults , fractures, joints and cavities in the basin of Kinta valley and led to widen it.

The climate conditions changed from wetter to drier and the strong rainfall decrease gradually and the atmosphere starts to clear. At the same time as the effect of rains become lesser and the sea surface temperatures start to return to normal. Growth starts again from the roots and seeds that remain on the ground or near the land surface and the lands were spotted with lakes and swamps. The occurrences of thin bed found beneath the cover soil of peat from the organic remains suggest that the development of swamps and marshes. Several positions were identified as swampy area from the deposits of organic gray clay presents in Figure 8.

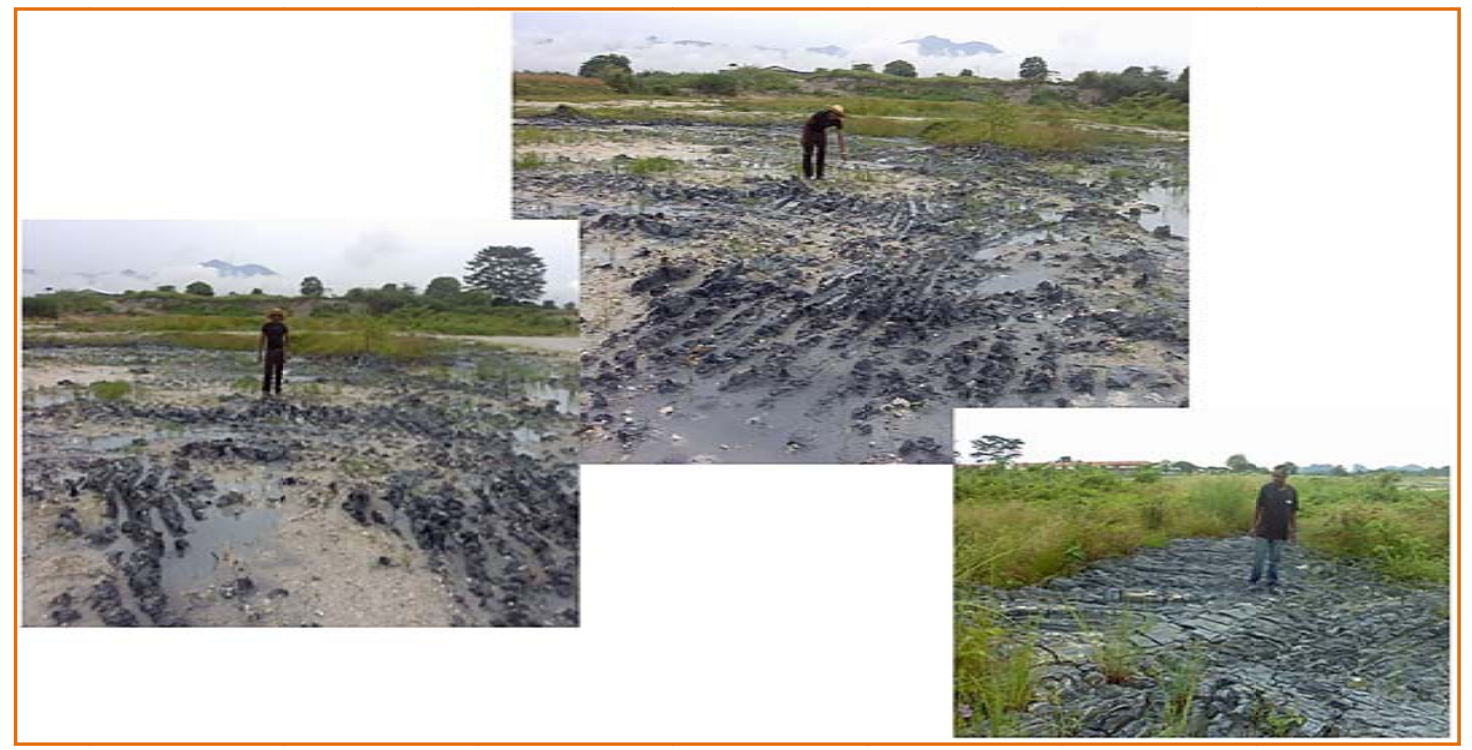

Figure 8. Land Photographs viewing several positions which were identified as swampy area from the deposits of organic gray clay

Subsequently the sea level return gradually between 2700 years BP till 1000 AP the sea level is equal to the present day sea level based on the regional topography and bathymetry (Hanebuth, et al., 2000).

This evidence proved that Kinta valley basin is full with water till the end of mid Holocene. Moreover, the archeological studies found that Perak old man 11000 years BP was living in a small cave found at Gua Gunung Runtuh mountain, located in Lenggong area in Ulu Perak to the north of Kinta valley and not found any indications for living Perak old man with huge caves in Kinta valley, the study area. Also archeological studies indicate that the sea water which reach Gunung Runtuh Mountain from the west and cover all Kedah land as mentioned before in the same time cover Kinta valley from the south.

\section{Field Survey Method}

\subsection{Geological Field Survey}

During the field inspection of the site, several active sinkholes were found and identified; it manifested as a narrow to medium-wide exposed throat. On average, sinkholes in the study area are from 1 to $24 \mathrm{~m}$ in diameter, with some having approximately the same range in depth.

Surface water can induce erosion along the frame of a sinkhole and cause its enlargement, reaching several meters long. Due to the interconnected nature of the karst features system, a group of small sinkholes observed in the study area is also capable of bonding to create an appearance of a larger sinkhole. This might enforce the thought that the small active sinkholes might be connected to one or more of the larger sinkholes (in diameter) by a series of groundwater conduits. There may be seep of water at the subsurface, with conduits for seep-water to a local lake, snaking along the base of slope to the east side. Tubular voids of visually undetermined depth infilled with clay or air karstic cavities were present, which could potentially threaten the integrity of these sites. Some features in the upper most layers of the subsurface due to the effects of meteoric water in a several points 
in the study area present in figure 9.

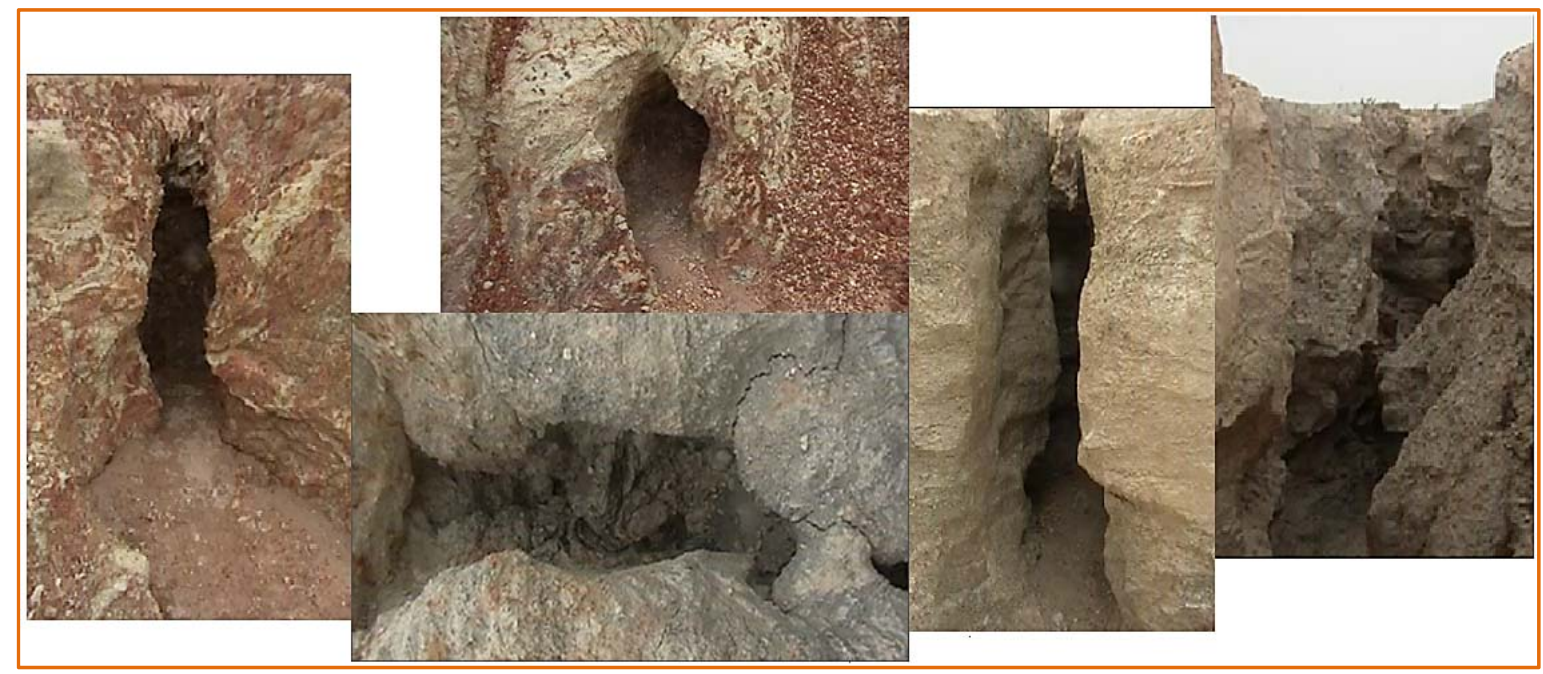

Figure 9. Land Photographs viewing some features in the upper most layer of the subsurface due to the effects of meteoric water in a several points the study area

Originally, sinkholes are made of steep or nearly vertical sidewalls. The portions of the sidewalls can break off over time, and fall into the sinkhole. This continuous process will enlarge the sinkholes, and it might invariably deepen if water is continuously added into it. This phenomenon confirms that the size of the sinkholes varies over time.

Many empty (air-infill) sinkholes were discovered at this site, and the emptying or infilling of these sinkholes forms the foundation of the stripping of topsoil and granules of sand, which drops down (in almost all of the study area) for reasons such as heavy runoff rains in the study area. Also, due to the difference in the topography of exposed rock, or due to the subsidence movement in the area, leading materials are channeled towards the sinkhole in order to fill the void in the layer beneath, or to fill the cavity through the existing joint/fracture in limestone bedrock. These sinkholes are only a few meters in diameter and depth, and their small size is due to the fact that the cavities in the limestone cannot progress to considerable sizes before they are filled in with sand. In some of the sinkholes, it is observed that one-side remains steep, and the opposite side forms a gentle slope. The sinkhole looks like a funnel that has been cut in half along its length, with a curvature of soil being apparent along the sidewall. This arch forms over the throat of the sinkhole and represents the roof of the void. The area above the soil arch, throat and the steep side is the most stable.

Over time, the sides of the sinkhole will continue to fall and fill in the hole. The sinkhole may reach a point that it will appear as a depression on the land surface, or it may be indistinguishable on a surface relief from the surrounding area. However, if there is a constant supply of water entering a sinkhole, a sinkhole can theoretically stay open for many years.

Several varieties of sinkholes were found and identified surrounding the site during groundwork inspection, some of it shown in figure 10. A total of 18 sinkholes were identified and given specific letters (A, B, C, D, E, F, G, H, I, J, K, L, M, N, O, P, Q and R). These sinkholes were not spotted in the satellite image of Perak at a scale 1/5000. Moreover, they were not observed in the satellite image of Google Earth for many reasons; first of all, the chosen satellite image may be older than the age of the sinkholes, meaning that these sinkholes were the result of recent developments. Secondly, sinkholes with smaller sizes were engulfed by plants, which in this case, compromised their visibility vis-à-vis satellite imagery. Additionally, the lake, which is a former tin mine, is clearly visible in the study area in this satellite image of google earth. A few of these sinkholes were selected to be analyzed by a high-resolution geophysical technique in order to achieve the case objectives. ERT in Wenner configuration was functional, which allows the imaging of the subsurface across and in proximity to many sinkholes as a primary stage to speculate on the origin of these sinkholes, recognize their shapes, and estimate their depths. 

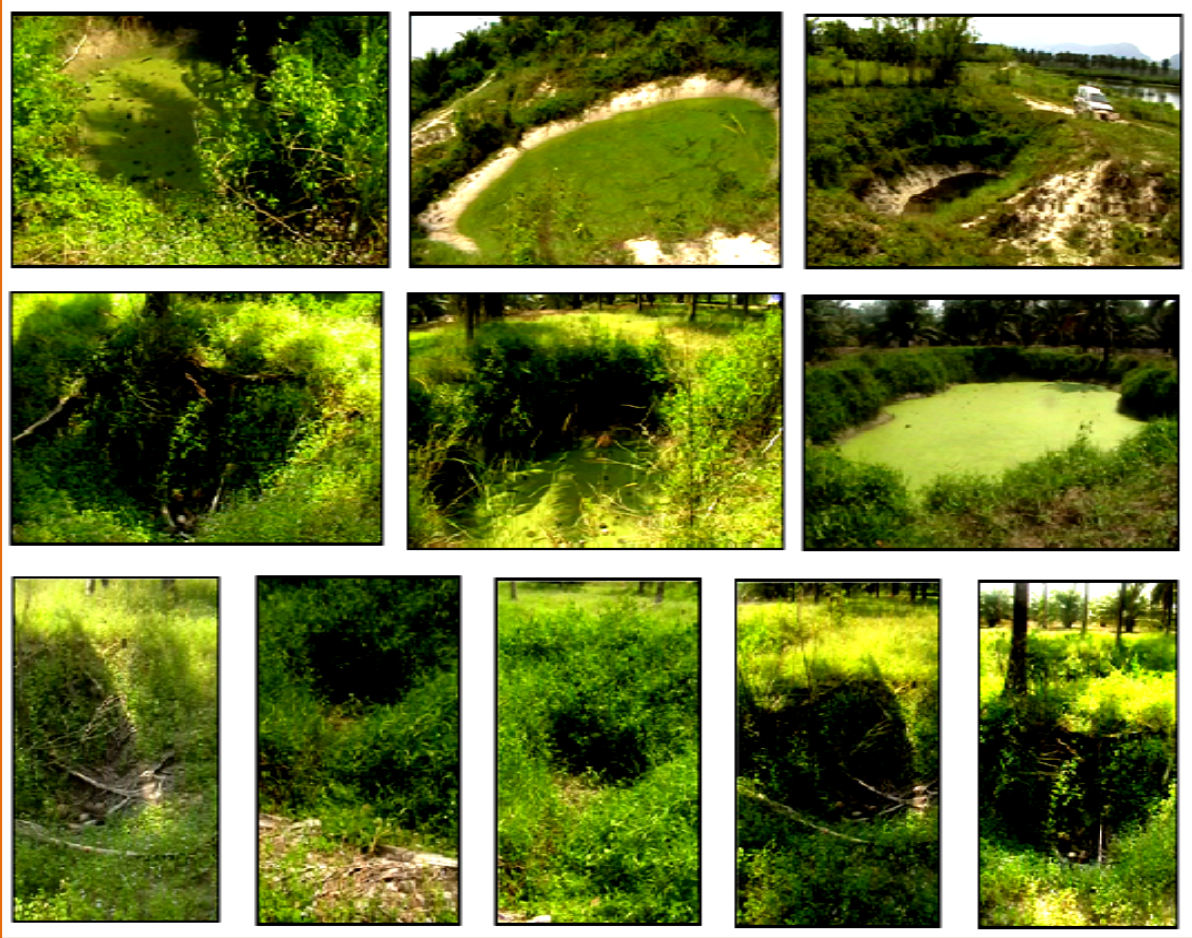

Figure 10. Several varieties of sinkholes were found and identified surrounding the site during the groundwork inspection

\subsection{Geophysical Field Survey}

\subsubsection{Instrumentation and Measurement Procedure}

The survey was carried out using a SAS1000 system, manufactured by ABEM Inc. of Sweden. Generally, this resistivity tool provides a greater combination of spatial resolution and depth of the investigation on the karst terrain than any other geophysical technique. The resolution provided by the resistivity technique is a function of the electrode spacing and other factors, including subsurface heterogeneity and conductivity contrasts. The depth of investigation is a function of the length of the employed two-dimensional arrays.

Two-Dimensional (2-D) electrical resistivity imaging/tomography surveys were carried out, and employed a large number of electrodes using 41 channels and an array of Wenner configurations were displayed at the site. These consisted of five traverses or profiles, spaced at $10-\mathrm{m}$ intervals, oriented in (NE $25^{\circ} \mathrm{SW}$ ) perpendicular to the trending of sinkholes in the study area. The length of each profile is $200 \mathrm{~m}$. Normally, a constant spacing between adjacent electrodes is used. The electrode spacing of $5 \mathrm{~m}$ is deemed adequate in this case.

These electrodes were connected to a multi-core cable Griffiths DH and Barker, R. D. (1993), configured in a Wenner array. The multi-core cable is attached to an electronic switching unit, and is used to automatically select the applicable four electrodes for each measurement. The typical setup for a 2-D survey with a number of electrodes along a straight-line attached to a multi-core cable and the instrument type SAS300, which was used in the survey and is demonstrated in Figure 11. 


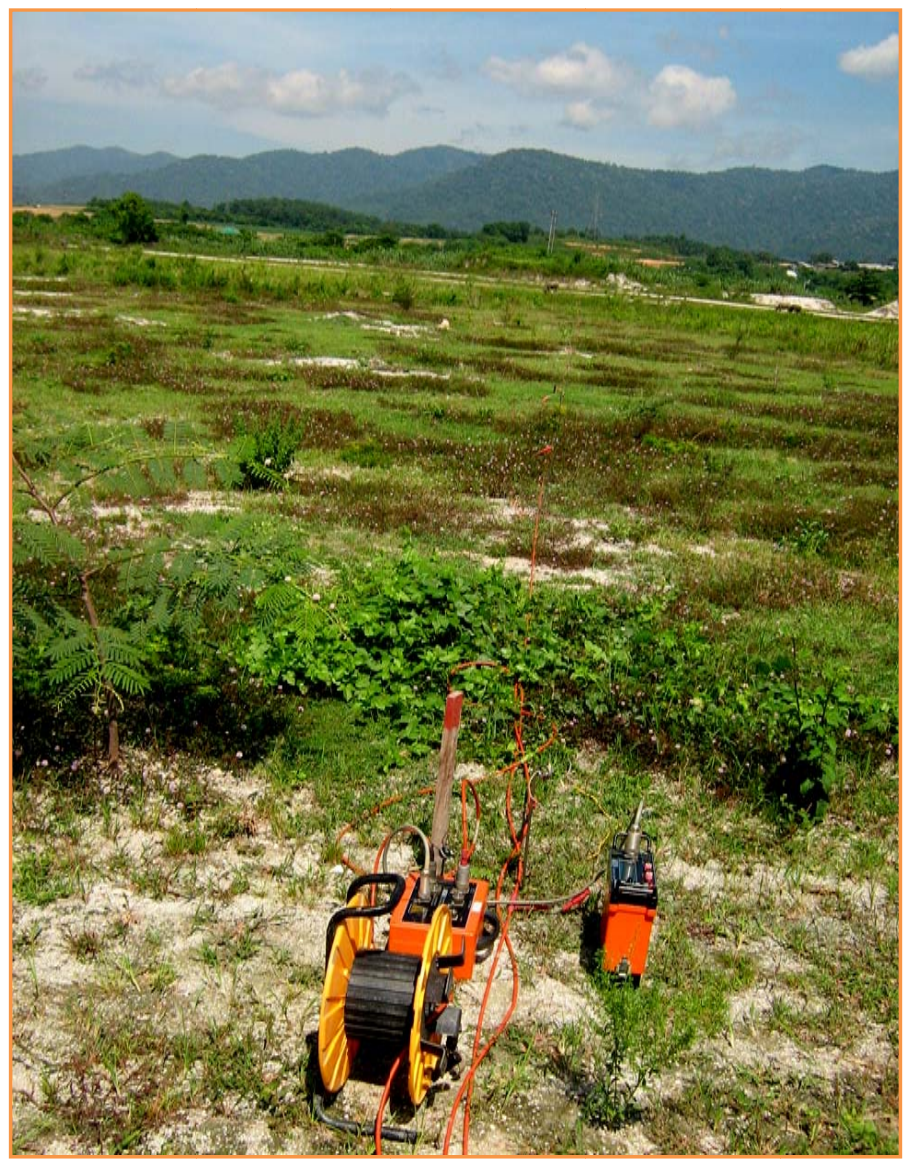

Figure 11. Demonstrate the instrument type SAS300 used in the survey and the typical setup for a 2-D survey, with a number of electrodes along a straight-line attached to a multi-core cable

The field systems have a built-in microprocessor system, which codes the sequence of measurements to take the type of array to use, while other survey parameters such as the current to use is normally entered into a text file. This is read by a computer program in a field system's computer. Different resistivity meters use different formats for the control file, which means that it will need to refer to the system's manual. After reading the control file, the computer program automatically selects the appropriate electrodes for each measurement, which is the very advantage of this system, especially in the context of a rugged terrain.

In a typical survey, most of the fieldwork involves laying out the cable and electrodes. After that, the measurements are automatically taken and stored in the computer device. To obtain a good 2-D picture of the subsurface, the coverage of the measurements must be all correct. In order to get the best results, the measurements in a field survey should be carried out in a systematic manner so that all the possible measurements are made as far as possible. This will affect the quality of the interpretation model obtained from the inversion of the apparent resistivity measurements Dahlin, T. and Loke, M.H. (1998).

As the electrode spacing increases, the number of measurements decreases. The number of measurements that can be obtained for each electrode spacing for a given number of electrodes along the survey line depends on the type of array used. The Wenner array provides the smallest number of possible measurements, compared to the other common arrays that were used in 2-D surveys.

\section{Data Collection}

Electrical resistivity data were collected along a relatively 2-D electrical resistivity profiles applied across and in proximity to many sinkholes located at this site. On average, 190 data points were collected for each 41-electrode in one profile, and on average, about 950 data points were collected for a total of five profiles at this site. The location of resistivity profiles (1-5) in the satellite image of Google Earth are in Figure 12. 


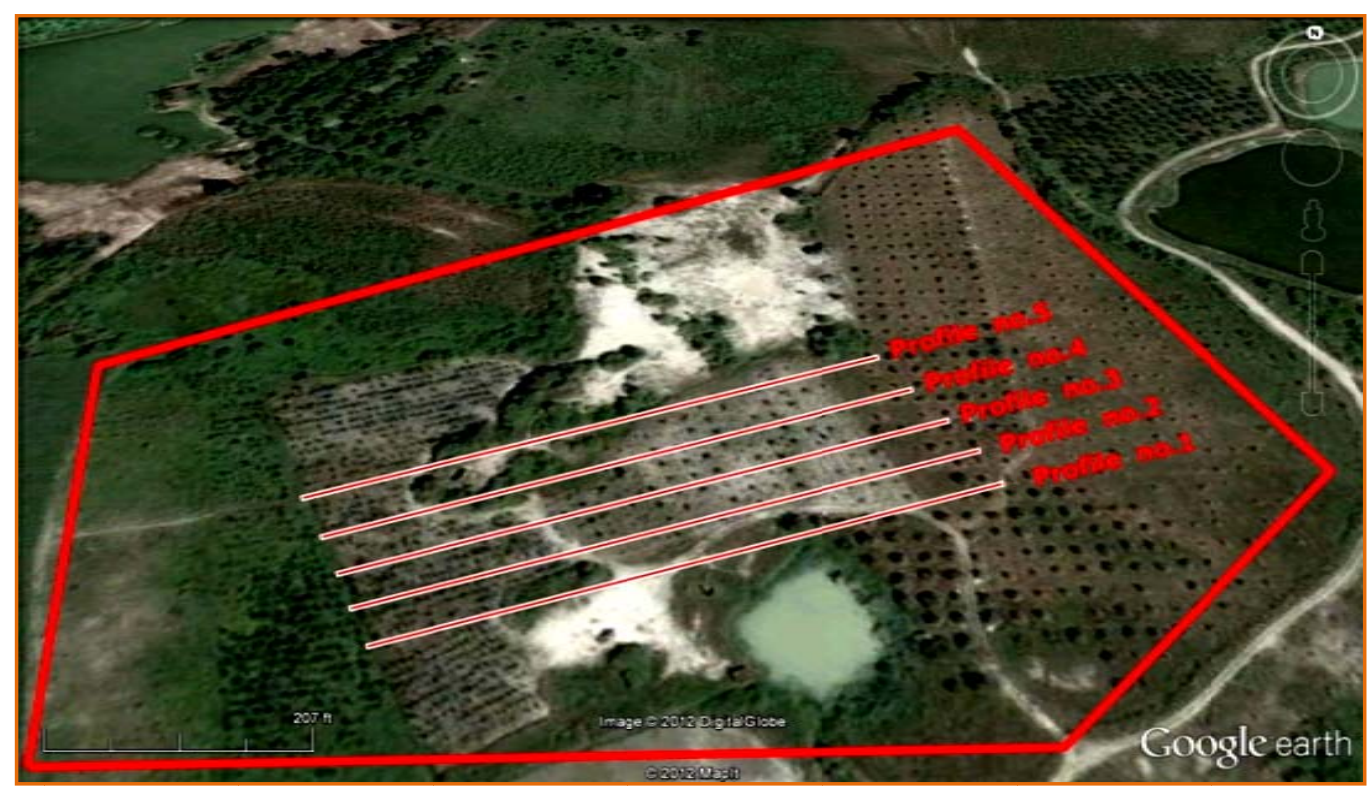

Figure 12. Satellite image of Google Earth viewing the location of resistivity profiles (1-5) in the studied site

\section{Data Processing}

After the geophysical field survey, the resistivity measurements are usually concentrated on the apparent resistivity values. Practically all of the commercial multi-electrode system comes equipped with computer software RES2DINVver.3.54. This inversion software was developed by Loke, M.H., \& Barker, R.D. (1994). The SAS instrument is connected to a laptop computer via a special cable, which enables data transfer that was processed to generate the 2-D resistivity models of the subsurface. It assumes that the subsurface is uniformly layered; consequently, lateral smoothing will occur in non-layered strata. This step converts the apparent resistivity values into a resistivity model section, which can be used for geological interpretation. The data is already inputted into RES2DINVver.3.54. Format. The conversion program is provided in a bundle with many commercial systems.

The bad data points, caused by different problems such as poor ground contact for a few number of electrodes, should contain significantly higher errors than the excellent data points. The bad data points, with the error distribution might show a more complicated pattern, and as a general rule, data points with errors of $100 \%$ and above can be removed.

In this survey, the computed root mean square (RMS) errors indicated that the difference between the measured resistivity values and those calculated from the true resistivity model was less than $10 \%$ of the RMS value, indicating a close match, as defined by the convergence limit. The default value with the average RMS error of $6.46 \%$ is the change in the RMS error between iterations, with a minimum of $4.0 \%$, and a maximum of $8.3 \%$. Most of the error in data reading may be due to the difficulty in penetrating the electric current through the ground surface, which may be due to the presence of large amount of friable sand and rock fragments due to mining activity in the surface of this site.

\section{Analysis and Interpretation of Electrical Resistivity Data}

The ERT technique applied in this geo-electrical survey to imaging the shallow subsurface from a depth of less than $2.0 \mathrm{~m}$, to a maximum depth of less than $29.0 \mathrm{~m}$. This technique was used in the karstified carbonate regions as a function to investigated karst features such as sinkholes, cavities, depressions and channel pipes. The survey found that this tool is suitable for differentiating surficial soil, clay, sand; weathered marbleized limestone bedrocks, intact marbleized limestone bedrocks and water- and air-filled cavities. Also, it was applied due to its requiring less effort and more time effective. It is based on the application of electric current into analyzed bedrock and measuring the intensity of electric resistivity to its conduit. Basically, it gives information of electric resistivity properties through the analyzed material towards electrical current passage, Telford, W.M. et al. (1990).

Several reports and researches on application of geophysical techniques in many karst terrains in several countries around the world were examined. These reports and researches are done by Anderson NL, et al. (2007). 
Furthermore, additional research was done by Louis IF et al. (2002). Moreover, other research was completed by Yassin, R.R. (2002) and Zhou, et al. (2000). Finally, earlier research was completed by Yahia et al. (1992). These reports enabled the determination of the electrical variables associated with the nature of sediments. Conclusions were made based on the variations in electrical resistivity values related with the nature of sediments.

The geological classification permits the successful imaging of the bedrock and subsurface karstic features, because soil, sand, clay, carbonate rock and air-filled cavities can normally be differentiated and mapped.

\section{Clay}

Are usually distinguished by low apparent resistivity's and variables, which are dependent on moisture, mineral content, purity, and unit shape/size, usually from $5 \mathrm{ohm}-\mathrm{m}$ to less than $60 \mathrm{ohm}-\mathrm{m}$. In this case, the clay is divided into many types with different colours, which is used in this resistivity section as:

- Highly moisturized soft clay is usually distinguished by insufficient low apparent resistivity with water filled porosity or very high mineralized. And is typically given pink colour in this study.

- Soft clay with pond water content is usually distinguished by extremely low resistivity and has very high conductivity or highly mineralized. And is typically given dark blue colour in this study.

- Moderate moisturized soft clay is usually distinguished by Very low apparent resistivity and has very high conductivity or moderate mineralized. And is typically given light blue colour in this study.

- Clay with low-moisturized are usually distinguished by low apparent resistivity or with low mineralized content. And is typically given yellow colour in this study.

\section{Sand}

Is usually characterize by medium apparent resistivity and variables, depending on the moisture content, purity and unit size, usually from $70 \mathrm{ohm}-\mathrm{m}$, to less than $160 \mathrm{ohm}-\mathrm{m}$. The sand is also divided into many types; its colouring scheme described below:

- Sand, distinguished by medium apparent resistivity, is typically dark green colour in this study.

- Sandy clay, distinguished by its low medium apparent resistivity, is typically given light green colour in this study.

Weathered limestone rock

- Comparatively weathered limestone rock is typified by high apparent resistivites, typically more than 200 ohm-m, to less than $400 \mathrm{ohm}-\mathrm{m}$, is typically given gray colour in this study.

\section{Intact limestone rock}

- Is distinguished by higher apparent resistivity, naturally from more than $400 \mathrm{ohm}-\mathrm{m}$ to more than 3000 ohm-m, and varies depending on layer thickness, its impurities and moisture content. It's given a light purple colour in this study.

\section{Intact pure marbleized limestone or dolostone rocks}

- Is distinguished by higher apparent resistivity, naturally from more than $4000 \mathrm{ohm}-\mathrm{m}$ to more than 8000 ohm-m, and varies depending on layer thickness, its impurities and moisture content. It's given a dark purple colour in this study.

\section{Air-filled cavities or voids}

- Are generally characterized by very high apparent resistivity, usually more than $3000 \mathrm{ohm}-\mathrm{m}$ to less than $6000 \mathrm{ohm}-\mathrm{m}$, but varies depending on the conductivity of the nearby strata and size/shape of void or cavity. Classically, it takes a black colour in this study.

Hence, electrical resistivity values were resolute for each rock unit. The results are tabulated in Table 1 . This table was suitable for investigation karst features and its deposits within karst terrains. Also in the same time was suitable for detecting any mineral deposits within the sediments in the area but it need experience for that. 
Table 1. Describes the range of resistivity values with the expected geological unit deposits to and to define the cave, cavity and sinkhole with air-infill

\begin{tabular}{|c|c|c|c|}
\hline No. & Range of resistivity values & Expected geological units deposits & $\begin{array}{l}\text { Color of Res. units } \\
\text { in ERT model }\end{array}$ \\
\hline 1. & $0 \Omega-\mathrm{m}-5 \Omega-\mathrm{m}$ & $\begin{array}{l}\text { Insufficient low resistivity, Soft clay with water filled } \\
\text { porosity, very high mineralized. }\end{array}$ & \\
\hline 2. & $5 \Omega-\mathrm{m}-10 \Omega-\mathrm{m}$ & $\begin{array}{l}\text { Extremely low resistivity and very high conductivity, } \\
\text { soft clay with ponded water, highly mineralized. }\end{array}$ & \\
\hline 3. & $10 \Omega-\mathrm{m}-20 \Omega-\mathrm{m}$ & $\begin{array}{l}\text { Very low resis tivity and very high conductivity, Clay } \\
\text { moderate mineralized. }\end{array}$ & \\
\hline 4. & $20 \Omega-\mathrm{m}-50 \Omega-\mathrm{m}$ & $\begin{array}{l}\text { Clay low mineralized, low resistivity and very high } \\
\text { conductivity. }\end{array}$ & \\
\hline 5. & $50 \Omega-\mathrm{m}-70 \Omega-\mathrm{m}$ & Below average resistivity, soil, silty or sandy clay. & \\
\hline 6. & $70 \Omega-\mathrm{m}-100 \Omega-\mathrm{m}$ & Average resistivity, clayey or silty sand. & \\
\hline 7. & $100 \Omega-m-160 \Omega-m$ & Above average resistivity, sand friable, coarse grain. & \\
\hline 8. & $160 \Omega-\mathrm{m}-200 \Omega-\mathrm{m}$ & $\begin{array}{l}\text { Mostly high resistivity, transitional zone consists of } \\
\text { rockfragments and sand. }\end{array}$ & \\
\hline 9. & $>200 \Omega-\mathrm{m}-400 \Omega-\mathrm{m}$ & $\begin{array}{l}\text { high resistivity, weathered limestone, probably } \\
\text { consisting of wet joints or fractures and/or clay in- } \\
\text { fill, higher resistivity }\end{array}$ & \\
\hline 10. & $>400 \Omega-\mathrm{m}->3000 \Omega-\mathrm{m}$ & Very high resistivity, Compact or intact limestone. & \\
\hline 11. & $>3000 \Omega-\mathrm{m}-6000 \Omega-\mathrm{m}$ & Extremely high resistivity, Voids or cavity, air in-fill. & \\
\hline 12. & $>6000 \Omega-\mathrm{m}-8000 \Omega-\mathrm{m}$ & $\begin{array}{l}\text { Extraordinarily high resistivity, Intact pure } \\
\text { marbleized limestone or dolostone rocks. }\end{array}$ & \\
\hline
\end{tabular}

The geological classification are utilized in this geoelectrical survey that was described above it permits the successful imaging to mapping and differentiated bedrocks and subsurface karstic features. Because there is crossing point between the value of resistivity data of intact limestone and the value of resistivity data to define karst features in fill with air such as cave, cavity and sinkholes. The table above can use for twice time, one with resistivity from 3000 - $6000 \Omega$-m to define the cave, cavity and sinkhole with air-infill, table 1 . Also to define rock fragments of limestone with friable and coarse grains sand which containing high porosity with air. In the second time with resistivity from $3000-6000 \Omega-\mathrm{m}$ as intact limestone, table 2 . without mention to cavity and sinkhole with air-infill. 
Table 2. Describes the range of resistivity values with the expected geological unit deposits to define the weathered, intact limestone and intact marbleized limestone

\begin{tabular}{|c|c|c|c|}
\hline No. & Range of resistivity values & Expected geological units deposits & $\begin{array}{l}\text { Color of Res. units } \\
\text { in ERT model }\end{array}$ \\
\hline 1. & $0 \Omega-m-5 \Omega-m$ & $\begin{array}{l}\text { Insufficient low resistivity, Soft clay with water filled } \\
\text { porosity, very high mineralized. }\end{array}$ & \\
\hline 2. & $5 \Omega-m-10 \Omega-m$ & $\begin{array}{l}\text { Extremely low resistivity and very high conductivity, } \\
\text { soft clay with ponded water, highly mineralized. }\end{array}$ & \\
\hline 3. & $10 \Omega-m-20 \Omega-m$ & $\begin{array}{l}\text { Very low resis tivity and very high conductivity, Clay } \\
\text { moderate mineralized. }\end{array}$ & \\
\hline 4. & $20 \Omega-m-50 \Omega-m$ & $\begin{array}{l}\text { Clay low mineralized, low resistivity and very high } \\
\text { conductivity. }\end{array}$ & \\
\hline 5. & $50 \Omega-\mathrm{m}-70 \Omega-\mathrm{m}$ & Below average resistivity, soil, silty or sandy clay. & \\
\hline 6. & $70 \Omega-m-100 \Omega-m$ & Average resistivity, clayey or silty sand. & \\
\hline 7. & $100 \Omega-m-160 \Omega-m$ & Above average resistivity, sand friable, coarse grain. & \\
\hline 8. & $160 \Omega-m-200 \Omega-m$ & $\begin{array}{l}\text { Mostly high resistivity, transitional zone consists of } \\
\text { rock fragments and sand. }\end{array}$ & \\
\hline 9. & $>200 \Omega-\mathrm{m}-400 \Omega-\mathrm{m}$ & $\begin{array}{l}\text { high resistivity, weathered limestone, probably } \\
\text { consisting of wet joints or fractures and/or clay in- } \\
\text { fill, higher resistivity }\end{array}$ & \\
\hline 10. & $>400 \Omega-\mathrm{m}->3000 \Omega-\mathrm{m}$ & Very high resistivity, Compact or intact limestone. & \\
\hline 11. & $>3000 \Omega-m-6000 \Omega-m$ & Very high resistivity, Compact or intact limestone. & \\
\hline 12. & $>6000 \Omega-\mathrm{m}->8000 \Omega-\mathrm{m}$ & $\begin{array}{l}\text { Extraordinarily high resistivity, Intact pure } \\
\text { marbleized limestone or dolostone rocks. }\end{array}$ & \\
\hline
\end{tabular}

In the following analysis, key explanatory interpretations were prepared to the geophysical electrical data in the selected study areas. The classifications utilized were illustrated before in this geoelectrical survey for key interpretations of the geoelectrical data in order to understand the resistivity profiles and the function of sinkholes and other subsurface karstic features investigated at these sites. Also it was successfully used for exploration of mineral deposits in karst area, Yassin, R.R. (2002). The interpretation of resistivity data identifies the points illustrated in the objective of the study.

The acquired data was interpreted by applying the geological classification originating from the variations in electrical resistivity values, which describes the range of resistivity values with the expected geological units' deposit. Some of the boreholes were completed by auger to the depth of $10 \mathrm{~m}$ at some point, facilitating in the interpretation of covered sediments in the site. Figure 13(A-E) presents the inverse model of electrical resistivity section from profiles (1-5), showing the interpreted location of shallow karst features (cavities and sinkhole) in the study area.

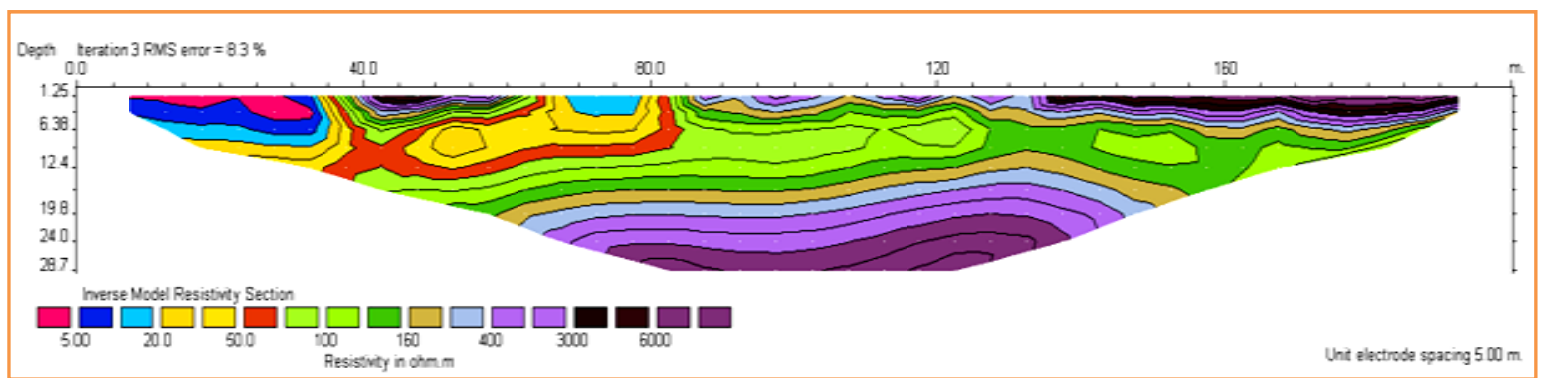

Figure (13 - A). Inverse model of electrical resistivity section for profile no.1



Figure (13 - B). Inverse model of electrical resistivity section for profile no.2 




Figure (13 - C). Inverse model of electrical resistivity section for profile no.3

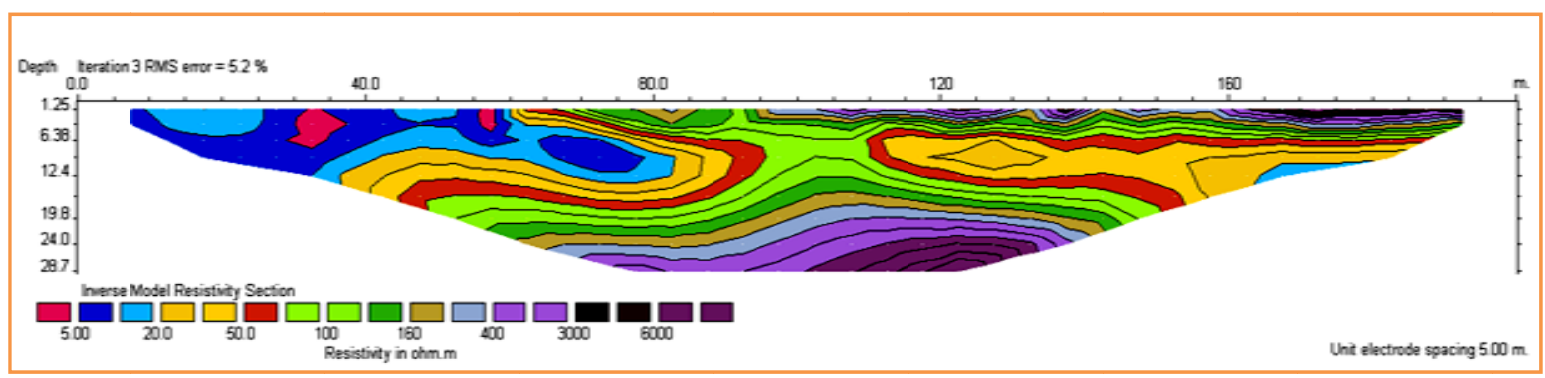

Figure (13 - D). Inverse model of electrical resistivity section for profile no.4

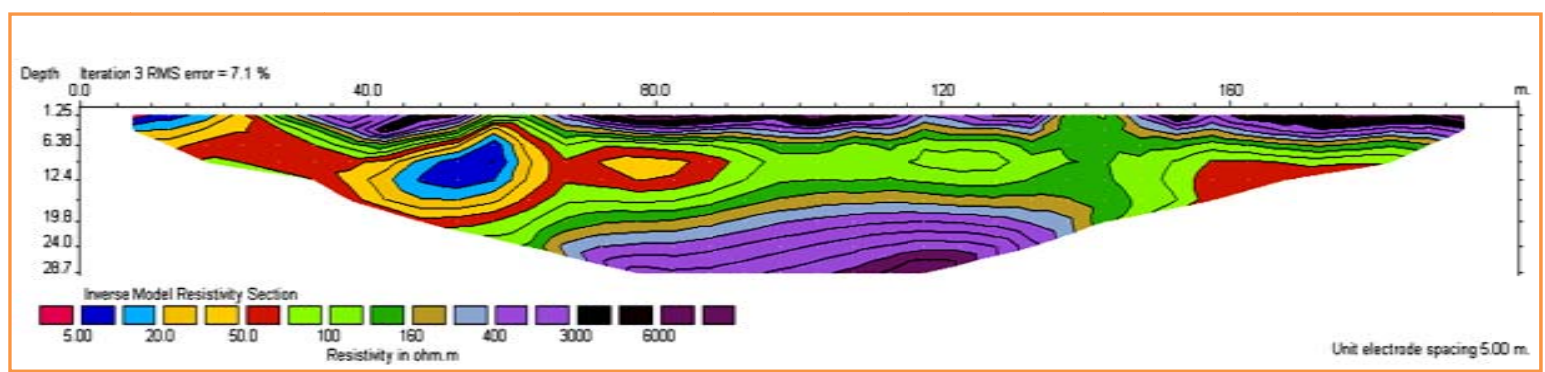

Figure (13 - E). Inverse model of electrical resistivity section for profile no.5

Figure 13(A-E). Inverse model of electrical resistivity section from profiles no. (1-5), viewing the interpreted location of shallow karst features (sinkholes and cavities) in the study area

Through the interpretation of E. R. Tomography section in profile no.1, figure (13-A), the upper most overlaying surface from the depth of $1.25 \mathrm{~m}-6 \mathrm{~m}$, and the proximity between the electrodes no.7\&12, 18\&22, 23\&25, 26\&27and electrode no. 28\&39 is characterized by high resistivites between $200 \mathrm{ohm}-\mathrm{m}$ to $3000 \mathrm{ohm}-\mathrm{m}$ and more, interpreted as stripped sand dry and friable, with remnants of limestone rock or other rock fragments, extracted by earth moving equipment from the pits of mine, due to previous mining and excavation operations, and is found covered along the profiles of the study area .

In this sand, collapses or subsidences were identified, one between electrode no.7\&12 and the others between electrode no.32\& electrode no.33, 36\&37. These represent cover-collapse sinkholes which occurred in the soil or other loose material resembling sand. with small diameter of $\sim 2 \mathrm{~m}-\sim 5 \mathrm{~m}$, and with a depth approximately between $\sim 3 \mathrm{~m}$ and $\sim 6 \mathrm{~m}$ from the ground surface. When the geophysical data corresponds to the geological site inspection, it will match the interpretation. These small sinkholes the bottom half comprises of sand and other remnant of rock fragments. The top half was characterized mostly by resistivites of $>3000 \mathrm{ohm}-\mathrm{m}$, representing an air in-fill.

Also depression observed in ERT section extended in between electrode no.8\&14 from the upper most surface to a depth of $5.50 \mathrm{~m}$ packed with sand dry and friable and remnants of limestone rock or other rock fragments. Appears due to the wetter area in the subsurface which led the surface to plunging down due to the weight of material that fills this depression.

In this profile an anomaly with low- very low resistivities represents semi-lens or a wetter area of moisturized clay determine in ERT section. Besides it's observed in the field survey extended almost between electrodes 
no.2\&8, with a depth of $>12.4 \mathrm{~m}$. Sinkhole in-fill with soft moistures clay extended from electrode no. 14 to $17 \& 18$, with a depth of $\sim 9 \mathrm{~m}$. It seems that the water drain through channel connect with wetter area in the subsurface beneath electrode no.7 at a depth of $\sim 12 \mathrm{~m}$. It's possible that the source of this water is meteoric or supply fresh water for palm trees irrigation accumulates in the subsurface and led the area to subsidence with mostly about $0.45 \mathrm{~m}$.

Through the interpretation of E. R. Tomography section in profile no.2, figure (13-B), main location with subsidence appearing on section extends in between electrode no.2 \&19, representing a semi-tabular shaped anomaly, reaching a depth of $>14 \mathrm{~m}$ contains clay saturated with water. This anomaly extended from profiles no.1 to profiles no.5, widening in the direction of profile no.4, and appears in this profile between electrode no. 2 \& 20 to reach maximum depth of $>17 \mathrm{~m}$. This anomaly was sliming in profile no.5. Moreover, the depth of this anomaly was increased from the depth of $12.4 \mathrm{~m}$ in profile\#1, to reach a depth of $19.8 \mathrm{~m}$ in profile no5.

This anomaly contains lenses of clay saturated with meteoric water. Deposits with several categories of resistivity values also appear in this feature. The first value, mostly with very low to low resistivity values, represents soft and moisturizing clay and less moisturizing clay, while materials with medium resistivity values represent the remnant of dispersive surficial soil or silty clay. Moreover, materials with medium-higher resistivites represent silty sand and sand. This subsidence area affected the surface of the study area and is apparently detected throughout the site inspection.

In profile no.2 as well delineated cover soil -collapse sinkhole extended mostly in between electrodes no. $23 \& 24$ and electrodes 25, in -fill with water and moisturized clay. The mouth of sinkhole was open and connected to the surface, this observed in site work inspection. With depth starting from the upper most surface of $1.25 \mathrm{~m}$ down to $13.50 \mathrm{~m}$ in the subsurface. The extremely high resistivity (3000-6000) Ohm-m in the upper part of the sinkhole it's due to vacant with air or unfilled.

Also in this profile determined two lenses of clay crammed in the sand. The first lens extended in between electrodes 26\&28; define in the depth approximately between $6-13 \mathrm{~m}$ in the subsurface. This lens with moderate size connected to the sinkhole mentioned before. The second lens with big size extended in between electrodes no. 29\&30 and electrode 37 ; define in the depth approximately between $6.36-17.5 \mathrm{~m}$ in the subsurface. In the center of these two lenses, low resistivity values were detected, representing clay. Surrounded by materials with less great or below average resistivites i.e. soil or silty clay.

Through the interpretation of E. R. Tomography in profile no.3, shown in figure (13-C), it is concluded that when the geophysical data interpretation corresponds with the geological site inspection, many subsurface karst features in the shape of sinkholes and cavities with semi- round or oval-shapes will appears along this profile. Some of that water in-fill, others with clay soft or moisturized in-fill or soil, silty clay, sandy clay and sand in-fill. While some of it were empty air in-fill. Additionally, one void was located along this profile, air in-fill.

The first karst feature appears in the subsurface as a cavity at approximately the central point of this profile, almost between electrode no. 20 \&23, mostly covered by friable sand and rock fragments on the surface. Start with a depth of $\sim 2 \mathrm{~m}$ from the ground surface to reach a depth of $\sim 12.4 \mathrm{~m}$, being approximately of $\sim 15 \mathrm{~m}$ wide. In cross-section, it appears in an oval-shape, with semi rounded walls and a relatively rounded base. At the center of this cavity, low resistivity values were detected, representing clay in-fill and other materials with less greater or below average resistivites i.e. soil or silty clay, surrounded by materials with greater resistivites i.e. silty sand. However, this cavity is active due to the existence of the amount of soil and some clay in the center, and the cover material was very thin, and might collapse in the near future under any load, to form a sinkhole ,figure (13-C).

The second karst feature appears as a cover-collapse sinkhole, detected almost beneath electrodes no.24 and in between electrodes no. $28 \& 29$ were approximately of $\sim 22.5 \mathrm{~m}$ diameter. The mouth of this sinkhole was open and connected to the surface, starting with the depth of $1.25 \mathrm{~m}$ in the ground's surface to reach a depth of 12.5 $\mathrm{m}$. In the cross-section, it is oval in shape, with semi-rounded walls and a relatively round base. This sinkhole is almost in-filled with very low resistivity values material representing moisturized clay. Other materials low resistivity values representing clay with less resistivities i.e. soil or silty clay, are surrounded by materials with greater resistivities i.e. silty sand, figure (13-C). However, this sinkhole is very active due to the existence of large amounts of clay and other material i.e. moisturized clay, soft clay, soil or silty clay and silty sand may be subjected to piping under any load.

The third karst feature appears in the subsurface as a cover-collapse sinkhole in the right flank of this profile in between electrodes no. $29 \& 30$ to electrodes 31 . This sinkhole is $~ 7.5 \mathrm{~m}$ diameter in a semi- round shape. The mouth is open and connected to the surface, starting with the depth of $1.25 \mathrm{~m}$ in the subsurface to reach a depth of 
$\sim 9 \mathrm{~m}$. In the cross section, it appears to have semi-rounded walls and a relatively semi-rounded base. Low to medium low categories of resistivity values were observed in this sinkhole, representing clay and remnants of dispersive surficial soil or silty clay, and are also patterned with greater medium resistivites i.e. silty sand. The upper most of this sinkhole show very high resistivity values were illustrated because this sinkhole is air in-filled till a depth of $\sim 3 \mathrm{~m}$ from the surface, figure (13-C).

Many empty sinkholes (air-infill) found at this site it was assumed that non-filling of the sinkhole was the foundation stripping of the portion of the top soil and granules of sand that were channeled down, due to the runoff of heavy rains over the surface in the study area, channeling the material from the sinkhole towards the smaller-sized cavity to fill via existing conduits. These sinkholes are a few meters in diameter and depth.

The fourth karst feature appears in the subsurface as a cover-collapse sinkhole on the right flank of this profile from electrode 33 and in between electrodes no. 34\&35. This sinkhole with open mouth connected to the subsurface, with $\sim 7.5 \mathrm{~m}$ diameter and $\sim 12.4 \mathrm{~m}$ deep. The high resistivity value is due to the fact that this sinkhole's air is infilled till the depth of $\sim 3 \mathrm{~m}$ from the surface, then in-filled with water. After the dissection of this sinkhole, the cross section appeared to have a pentagon shape, with a near-sharp and irregular wall, and a relatively semi-round base. Several categories of resistivity values were found in this sinkhole, first, very low low resistivity values, representing soft and moisturizing clay, less moisturized clay and material with medium resistivity values, representing remnant of dispersive surficial soil or silty clay, and also material with greater resistivites i.e. silty sand and sand, Figure (13-C).

The water remained in the sinkhole, suggesting that the flush or the migrates was stopped after the conduit or the pipe that were formed due to solution-widened joints became choked or blocked with clay and other materials in these drainage, due to the fact that the size of the cavities in the limestone bed rock are infilled or loaded with clay and sandy material.

Small sinkhole observed in the surface in-filled with friable sand and remnant rock fragments from electrode no.28 to in between electrodes no. 29\&30, with $\sim 7.5 \mathrm{~m}$ wide in funnel-shaped, and reaches a depth of $\sim 9.5 \mathrm{~m}$. The center with very high resistivity of more than $4000 \mathrm{Ohm}-\mathrm{m}$, consider that void air in-fill were present at the subsurface, measuring $\sim 2.5 \mathrm{~m}$ wide and $\sim 3.25 \mathrm{~m}$ high, from a depth of $\sim 1.25 \mathrm{~m}$ to reach a depth of $\sim 4.5 \mathrm{~m}$.

The interpretation of E. R. Tomography section in profile no.4, shown in figure (13-D) displays beside the semi-tabular shaped anomaly which present a wetter area of clay saturated with water which determine and mentioned before in left flank, extended almost between electrodes no.2\&20 to reach maximum depth of $>17 \mathrm{~m}$ in this profile. The upper most overlaying surface from the depth of $2 \mathrm{~m}$ to nearly $5 \mathrm{~m}$, in the right flank of this profile in the proximity in between the electrodes no. $17 \& 18$, electrode no.20\&26, electrode no.27\&28, electrode no. 29\&31and in between the electrode no. 33\&39 is characterized by high resistivites between $200 \mathrm{ohm}-\mathrm{m}$ to $3000 \mathrm{ohm}-\mathrm{m}$ and more, interpreted as stripped sand dry and friable, with remnants of limestone rock or other rock fragments, extracted by earth moving equipment from the pits of mine, due to previous mining and excavation operations.

In this stripped sand, several small collapses or subsidences were visible and identified in the ground surface of this profile. A few represent cover-collapse sinkhole with small diameter of $\sim 2 \mathrm{~m}$ to maximum $\sim 3 \mathrm{~m}$, with a depth approximately between $\sim 3 \mathrm{~m}$ and $\sim 4 \mathrm{~m}$. It's found between electrode no. $17 \& 18$, electrode no. $25 \& 26$, electrode no.28\&29, electrode no.35\&36. When the geophysical data corresponds to the geological site inspection, it will match the interpretation. These small sinkholes comprises of sand and other remnant of rocks. Some of the profile characterized mostly by high resistivites of $>4000 \mathrm{ohm}-\mathrm{m}$, due to the extra size of gaps with air in-fill between the sand and the rock fragments.

Underneath this friable sand and rock fragment there is layer of sand. Longitudinal anomaly represent longitudinal channel extended in the subsurface between electrodes no.23 \&39,from depth almost between 4 to $6 \mathrm{~m}$ down to $19 \mathrm{~m}$, in the left flank of this profile consider it due to movement of subsurface water from the sinkhole in right flank of this profile only. This channel in-fill with material of very low resistivity values represents high moisturized clay. The other material of low resistivity values represents stiff clay. Surrounded by materials with less resistivites i.e. soil or silty clay and materials with greater resistivites i.e. silty sand.

The interpretation of E. R. Tomography section in profileno.5, shown in figure (13-E) displays the enormous lens or cavity in pear shape appearing in a semi-tabular shaped anomaly that mentioned the four profile before , continuing to the left flank from electrode no. 8 to in between electrode no. $14 \& 15$, at about $\sim 32.50 \mathrm{~m}$ wide. This lens started in the subsurface, from a depth of $\sim 2 \mathrm{~m}$, reaching a depth of $\sim 21 \mathrm{~m}$. Several categories of resistivity values were observed in this lens, first mostly very low - low resistivity values, representing soft and moisturizing clay and less moisturized clay, while material with medium resistivity values represents the remnant 
of dispersive surficial soil or silty clay.

This cavity or lens combines with the main horizontal trend anomalies. The considerations led to the conclusion that these cavities are recently developed and support the assumption that the origin of this cavity was the presence of conduit feature, likely widened in the study area, and had been rapidly filled with clay and other materials, figure(13-E). In the near - surface of the study area between electrodes no. $7 \& 12$ in this profile shows an area with subsidence, and it is assumed that this is due to the presence of this lens or cavity body in the subsurface which led the surface to plunging down due to the weight of material that fills this depression. This depression packed with stripped sand dry and friable, with remnants of limestone rock or other rock fragments.

Another lens in oval shape displays in a horizontal trend anomalies, connecting to the first lens in between electrode no. $14 \& 15$, to electrode no. 19 , at about $\sim 22.50 \mathrm{~m}$ wide. This lens started in the subsurface, from a depth of $\sim 6 \mathrm{~m}$, reaching a depth of $\sim 14 \mathrm{~m}$. Several categories of resistivity values were observed in this lens, first mostly low resistivity values, stiff clay, packed in material with medium resistivity values represents the remnant surficial soil or silty clay.

Channel pipe was observed in between electrodes no.28\&30. This pipe is in-filled with sand and proceeded as a conduit to flush material and meteoric water from the top surface down to the limestone bedrock. This conduit reaches a depth of $19.8 \mathrm{~m}$, feeding the subsurface with meteoric water.

Moreover the upper most overlaying surface from the depth of $1.25 \mathrm{~m}-6 \mathrm{~m}$, and the proximity in between the electrodes no.7\&12, electrode no.14\&24, electrode no. $25 \& 28$ and electrode no. $30 \& 39$ is characterized by high resistivites between $200 \mathrm{ohm}-\mathrm{m}$ to $3000 \mathrm{ohm}-\mathrm{m}$ and more, interpreted as stripped sand dry and friable, with remnants of limestone rock or other rock fragments, extracted by earth moving equipment from the pits of mine, due to previous mining and excavation operations, and is found covered along the profiles of the study area .

In this sand, several small collapses or subsidences were visible and identified in the ground surface of this profile one in between electrode no. $8 \& 9$, and the others in between electrode no. $16 \& 18$, electrode no. $23 \& 24$, electrode no.31\&32 and electrode no. 39\&37. These represent cover soil -collapse sinkhole and pipes with small diameter of $\sim 1 \mathrm{~m}$ to not more than $\sim 5 \mathrm{~m}$, with a depth approximately between $\sim 3 \mathrm{~m}$ and $\sim 5 \mathrm{~m}$ from the ground surface. When the geophysical data corresponds to the geological site inspection, it will match the interpretation. These small sinkholes from the bottom half comprises of sand and other remnant of rock fragments. The top half was characterized mostly by resistivites of $>3000 \mathrm{ohm}-\mathrm{m}$, representing an air in-filled. Also depression observed in ERT section extended in between $7 \& 12$ from the surface to a depth of $5.50 \mathrm{~m}$ packed with sand dry and friable and remnants of limestone rock or other rock fragments. Appears due to the wetter area in the subsurface which led the surface to plunging down due to the weight of material that fills this depression. The data base of karst features from (2-D) E R Tomography sections in (Kampung Kunsila estate) north west Kampar city were summarized in table 3.

Jointed limestone with high resistivity were detected at the shallowest subsurface below the tubular anomaly, extended in between electrode no.14\&32 in profile no.1, in between electrode no.13\&31 in profile no.2, between electrode no.14\&34 in profile no. 3 , and between electrode no.14\&29 in profile no.4 and profile no.5. Intact or compact limestone bedrock, characterized by higher resistivity, was observed beneath Jointed limestone, figure (13-A). The approximate depth mentioned in the Table-4, and can also be detected along other profiles in Figure (13-B, C, D, E), extended with different lengths and depths. Furthermore, pinnacles were clearly detected in many E. R. Tomography profiles sections. In profile no.1, it is detected beneath electrode no.27\& 28 at a depth of $10.5 \mathrm{~m}$, shown in figure (13-A), and in profile \#2,it is detected beneath electrode no. 21\&22, and reaching a depth of $\sim 12 \mathrm{~m}$, shown in figure (13-B). Furthermore, in profile \#3, it is located beneath electrode no. 18\&19, and reaches a depth of $\sim 12.5 \mathrm{~m}$. Beneath electrodes no.23\&24, it reaches a depth of $\sim 14.5 \mathrm{~m}$, while beneath electrodes no. 31\&32, and it reaches a depth of $\sim 11 \mathrm{~m}$, shown in figure (13-C). Moreover, it is clearly observed that profile no. 4 reaches a depth of $\sim 15.5 \mathrm{~m}$ beneath electrodes no.22\&23, shown in figure (13-D).The smoothing that was observed in the subsurface limestone bedrock is the result of employing the RES2DINVver.3.54. Software, which assumes that the subsurface is uniformly layered; and consequently lateral smoothing will form in a non-layered stratum. 
Table 3. Data base of karst features from (2-D) E. R. Tomography sections in (Kampung Kunsila estate) north west Kampar city

\begin{tabular}{|c|c|c|c|c|c|c|}
\hline \multicolumn{7}{|c|}{$\begin{array}{c}\text { DATA BASE OF KARST FEATURES FROM (2-D) E. R. TOMOGRAPHY SECTIONS IN ( KAMPUNG KUNSILA } \\
\text { ESTATE) NORTH WEST KAMPAR CITY }\end{array}$} \\
\hline $\begin{array}{l}\text { TRAVERSE } \\
\text { No. }\end{array}$ & KARST FEATURES & QUANTITY & LOCATION & SIZE & $\begin{array}{c}\text { APPROXIMATE } \\
\text { DEPTH }\end{array}$ & DESCRIPTIONS \\
\hline \multirow{6}{*}{ Profile no.1 } & $\begin{array}{l}\text { cover-collapse } \\
\text { sinkhole }\end{array}$ & 1 & E14-E17\&188 & $7.5 \mathrm{~m}$ Diameter & $0.0 \mathrm{~m} \cdot 9.0 \mathrm{~m}$ & $\begin{array}{l}\text { In-fill with non stiff and moisturized } \\
\text { clay. }\end{array}$ \\
\hline & $\begin{array}{l}\text { cover-collapse } \\
\text { sinkbole }\end{array}$ & 1 & E7\&8-E9\&10 & $\begin{array}{l}4.5-5 \mathrm{~m} \\
\text { Diameter }\end{array}$ & $0.0 \mathrm{~m} \cdot 5.0 \mathrm{~m}$ & \multirow{3}{*}{$\begin{array}{l}\text { The bottom half comprises of sand and } \\
\text { other remnant of rock fragments. The } \\
\text { top half was air in-fill. }\end{array}$} \\
\hline & $\begin{array}{l}\text { Cover-collapse } \\
\text { sinkhole }\end{array}$ & 1 & E32 - E33 & 3m Diameter & $0.0 \mathrm{~m}-3.0 \mathrm{~m}$ & \\
\hline & $\begin{array}{l}\text { cover-collapse } \\
\text { sinkhole }\end{array}$ & 1 & E36-E37 & Sm Diameter & $0.0 \mathrm{~m}-6.0 \mathrm{~m}$ & \\
\hline & $\begin{array}{c}\begin{array}{c}\text { semi-lens or a wetter } \\
\text { area of moisturized } \\
\text { elay }\end{array} \\
\end{array}$ & 1 & $\mathbf{E} 2 \cdot \mathbf{E} 8$ & $30 \mathrm{~m}$ Wide & $<1.25 \mathrm{~m},>12.4 \mathrm{~m}$ & Clay saturated with water. \\
\hline & Depression & 1 & E8-E14 & $30 \mathrm{~m}$ vide & $1.25-5.5 \mathrm{~m}$ & $\begin{array}{l}\text { Packed with dry sand and friable and } \\
\text { remnants of limestone rock. }\end{array}$ \\
\hline \multirow{4}{*}{ Profile no.2 } & $\begin{array}{l}\text { Semi- tabular shaped } \\
\text { anomaly }\end{array}$ & 1 & $\mathbf{E} 2 \cdot \mathbf{E} 19$ & $30 \mathrm{~m}$ Wide & $<1.25 \mathrm{~m},>14.0 \mathrm{~m}$ & $\begin{array}{l}\text { Remnants of surface soll or silty elay } \\
\text { due to water activity. }\end{array}$ \\
\hline & $\begin{array}{l}\text { Soil eover-eollapse } \\
\text { sinkhole }\end{array}$ & 1 & $E 23 \& 24 \cdot E 25$ & $7.50 \mathrm{~m}$ Diameter & $1.25 \mathrm{~m}=-13.50 \mathrm{~m}$ & $\begin{array}{l}\text { Lower part with water in-fill and } \\
\text { molsturized clay. The upper part with } \\
\text { air or unfilled. }\end{array}$ \\
\hline & Moderate size lens & 1 & E26\& E28 & $10 \mathrm{~m}$ Wide & $6 \mathrm{~m} \cdot-13 \mathrm{~m}$ & $\begin{array}{l}\text { Contain stiff elay, silty elay or remnant } \\
\text { surficial soil. }\end{array}$ \\
\hline & Big size Lens & 1 & E29\&:30-E37 & $27.50 \mathrm{~m}$ Wide & $6.36 \mathrm{~m}-\sim 17.5 \mathrm{~m}$ & $\begin{array}{c}\text { Contain stiff elay, silty elay or remnant } \\
\text { surficial soil }\end{array}$ \\
\hline \multirow{6}{*}{ Profile no.3 } & Cavity & 1 & E20 - E23 & Size $10.4 \times 15 \mathrm{~m}$ & $2 \mathrm{~m}-\sim 12,4 \mathrm{~m}$ & $\begin{array}{l}\text { Bagged with stiff elay, soil or silty elay, } \\
\text { silty sand due to Karst processes. }\end{array}$ \\
\hline & $\begin{array}{c}\text { cover-collapse } \\
\text { sinkhole }\end{array}$ & 1 & E24-E28\&29 & $22.5 \mathrm{~m}$ Diameter & $1.25 \mathrm{~m}-12.5 \mathrm{~m}$ & $\begin{array}{l}\text { In-filled with moisturized clay, stiff clay, } \\
\text { soil or silfy elay. }\end{array}$ \\
\hline & $\begin{array}{l}\text { cover-collapse } \\
\text { sinkhole }\end{array}$ & 1 & E29\&:30 - E31 & $7.5 \mathrm{~m}$ Diameter & $1.25 \mathrm{~m}-9 \mathrm{~m}$ & $\begin{array}{l}\text { Clay and remnant surficial soll or silty } \\
\text { clay and silty sand. }\end{array}$ \\
\hline & $\begin{array}{c}\text { cover-collapse } \\
\text { sinkhole }\end{array}$ & 1 & E33 - E34\&35 & 7.5m Diameter & $1.25 \mathrm{~m}-12.4 \mathrm{~m}$ & $\begin{array}{l}\text { Clay and remnant surficial soil or silty } \\
\text { clay and silty sand. }\end{array}$ \\
\hline & $\begin{array}{l}\text { cover-collapse } \\
\text { sinkbole }\end{array}$ & 1 & E $28-E 29 \& 30$ & $7,5 \mathrm{~m}$ Width & $1.25 \mathrm{~m}-9.5 \mathrm{~m}$ & $\begin{array}{l}\text { In-filled with friable sand and remnant } \\
\text { rock fragments. }\end{array}$ \\
\hline & Void & 1 & E29-E30 & $2.5 \mathrm{~m} \times 3.25 \mathrm{~m}$ & $1.25 \mathrm{~m}-\sim 4.5 \mathrm{~m}$ & air in-fill. \\
\hline \multirow{4}{*}{ Profile no.4 } & $\begin{array}{c}\text { semi-tabular shaped } \\
\text { anomaly }\end{array}$ & 1 & E2 $-E_{20}$ & Extent $90 \mathrm{~m}$ & $1.25 \mathrm{~m}=\sim 17 \mathrm{~m}$ & Clay in-fill, due to Karst processes. \\
\hline & longitudinal channel & 1 & E23-E39 & Extent $80 \mathrm{~m}$ & $4 \mathrm{~m}--19 \mathrm{~m}$ & $\begin{array}{l}\text { High moisturized elay, stiff elay, soil or } \\
\text { silty clay and silty sand. }\end{array}$ \\
\hline & $\begin{array}{l}\text { cover - collapse } \\
\text { sinkhole and pipes }\end{array}$ & 4 & $\begin{array}{l}\text { E17-E18 } \\
\text { E25 }- \text { E26 } \\
\text { E28-E29 } \\
\text { E35 - E36 }\end{array}$ & 2-3m Diameter & $\begin{array}{l}1.25 \mathrm{~m}-\sim 3 \mathrm{~m} \\
1.25 \mathrm{~m}-\sim 4 \mathrm{~m}\end{array}$ & $\begin{array}{l}\text { The bottom half comprises of sand and } \\
\text { other remnant of rock fragments. }\end{array}$ \\
\hline & Depression & 1 & E40-E56 & width $-130 \mathrm{~m}$ & $0,0 \mathrm{~m}--17,0 \mathrm{~m}$ & Due to Karst processes. \\
\hline \multirow{10}{*}{ Profile no.s } & $\begin{array}{c}\text { Semi- tabular shaped } \\
\text { anomaly }\end{array}$ & 1 & E8-E14\&15 & $\sim 32.50 \mathrm{~m}$ wide & $\sim 2 \mathrm{~m} \cdot \sim 21 \mathrm{~m}$ & $\begin{array}{l}\text { Soft and moisturizing elay and less } \\
\text { moisturized clay and remnants of } \\
\text { Dispersive surficial soil. }\end{array}$ \\
\hline & Cavity & 1 & $E 8 \cdot 14 \& 15$ & $\sim 32.50 \mathrm{~m}$ wide & $\sim 2 \mathrm{~m} \cdot \sim 21 \mathrm{~m}$ & $\begin{array}{l}\text { Soft and moisturizing elay and less } \\
\text { molsturized clay and remnants of } \\
\text { Dispersive surficial soil. }\end{array}$ \\
\hline & Cavity & 1 & E14\&15 - E19 & $\sim 22.50 \mathrm{~m}$ wide & $\sim 6 \mathrm{~m} \cdot \sim 14 \mathrm{~m}$ & $\begin{array}{l}\text { Stiff elay and remnants of Dispersive } \\
\text { surficial soil or silty clay. }\end{array}$ \\
\hline & Depression & 1 & E7 - E12 & $\sim 25 \mathrm{~m}$ wide & $1.25 \mathrm{~m}=\sim 6.36 \mathrm{~m}$ & $\begin{array}{l}\text { Packed with stripped dry and friable } \\
\text { sand and remnants of limestone rock or } \\
\text { other rock fragments. }\end{array}$ \\
\hline & $\begin{array}{l}\text { cover-collapse } \\
\text { sinkhole and pipes }\end{array}$ & 5 & 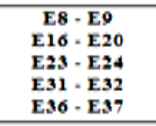 & $\sim 1 \mathrm{~m} * \sim 5 \mathrm{~m}$ & $-3 m--5 m$ & $\begin{array}{l}\text { The bottom half comprises of sand and } \\
\text { other remnant of rock fragments }\end{array}$ \\
\hline & $\begin{array}{l}\text { Lens or cavity in } \\
\text { pear shape }\end{array}$ & 1 & E8-E14\&15 & $\sim 32.50 \mathrm{~m}$ wide & $-2 m \cdot-21 m$ & $\begin{array}{l}\text { soft and moisturizing clay and less } \\
\text { moisturized clay, and remnant surficial } \\
\text { of Dispersive soil or silty clay }\end{array}$ \\
\hline & Lens in oval shape & 1 & E14\&15-E19 & $\sim 22.50$ wide & $\sim 6 \mathrm{~m} \cdot \sim 14 \mathrm{~m}$ & $\begin{array}{l}\text { Stiff clay, remnant of Dispersive } \\
\text { surficial soil or silty elay. }\end{array}$ \\
\hline & $\begin{array}{c}\text { Channel } \\
\text { Pipe/Conduit }\end{array}$ & 1 & E28-E30 & Sm wide & $1.25 \cdot-19.8 \mathrm{~m}$ & in-filled with sand \\
\hline & Depression & 1 & E11-E23 & $\begin{array}{l}\text { Length } ~ \\
60.0 \mathrm{~m}\end{array}$ & $0.0 \mathrm{~m} \cdot-9.50 \mathrm{~m}$ & $\begin{array}{l}\text { Packed with stripped dry and friable } \\
\text { sand, with remnants of limestone rock } \\
\text { and other rock fragments Due to Karst } \\
\text { processes. }\end{array}$ \\
\hline & Depression & 1 & $E 26-E 43$ & $\begin{array}{r}\text { Length } \\
\sim 160.0 \mathrm{~m}\end{array}$ & $0.0 \mathrm{~m} \cdot \sim 11.50 \mathrm{~m}$ & $\begin{array}{l}\text { Packed with stripped sand dry and } \\
\text { friable, with remnants of limestone rock } \\
\text { and other rock fragments Due to Karst } \\
\text { processes. }\end{array}$ \\
\hline
\end{tabular}




\section{Description of Sinkholes Determine in the Study Area}

Several varieties of sinkholes were discovered in the study area through the information and data record of geological and geophysical survey. Diagrammatic cross-sections illustrating the type of sinkholes in the study are presented in figure $14(\mathrm{~A}-\mathrm{C})$.

The first kind of sinkholes discovered is a few meters in diameter and depth, and are referred to as a soil coversubsidence or collapse. This type of sinkhole is formed where overburden is relatively thin in some regions; the limestone rocks were covered by a thin layer, more permeable and composed of a greater percentage of silt and sand, with a possible thickness between $15 \mathrm{~m}$ to $30 \mathrm{~m}$, with the slight presence of clay below it.

These layers are covered with soil. These layers are design with lacks of cohesiveness between the particles to form a significant "bridge" across the void where it occurs. The limestone rocks, which are sensitive to both physical and chemical and the natural dissolving processes, will eventually break down. When it collapses, a cavity or void usually forms. The dissolving granules of sand will drop down to fill this cavity or void. The small diameter and depth of these kinds of sinkholes are due to the fact that the open cavities were smaller, and cannot expand in order to reach the considerable size before they were in-filled with sand as illustrated in figure (14-A).

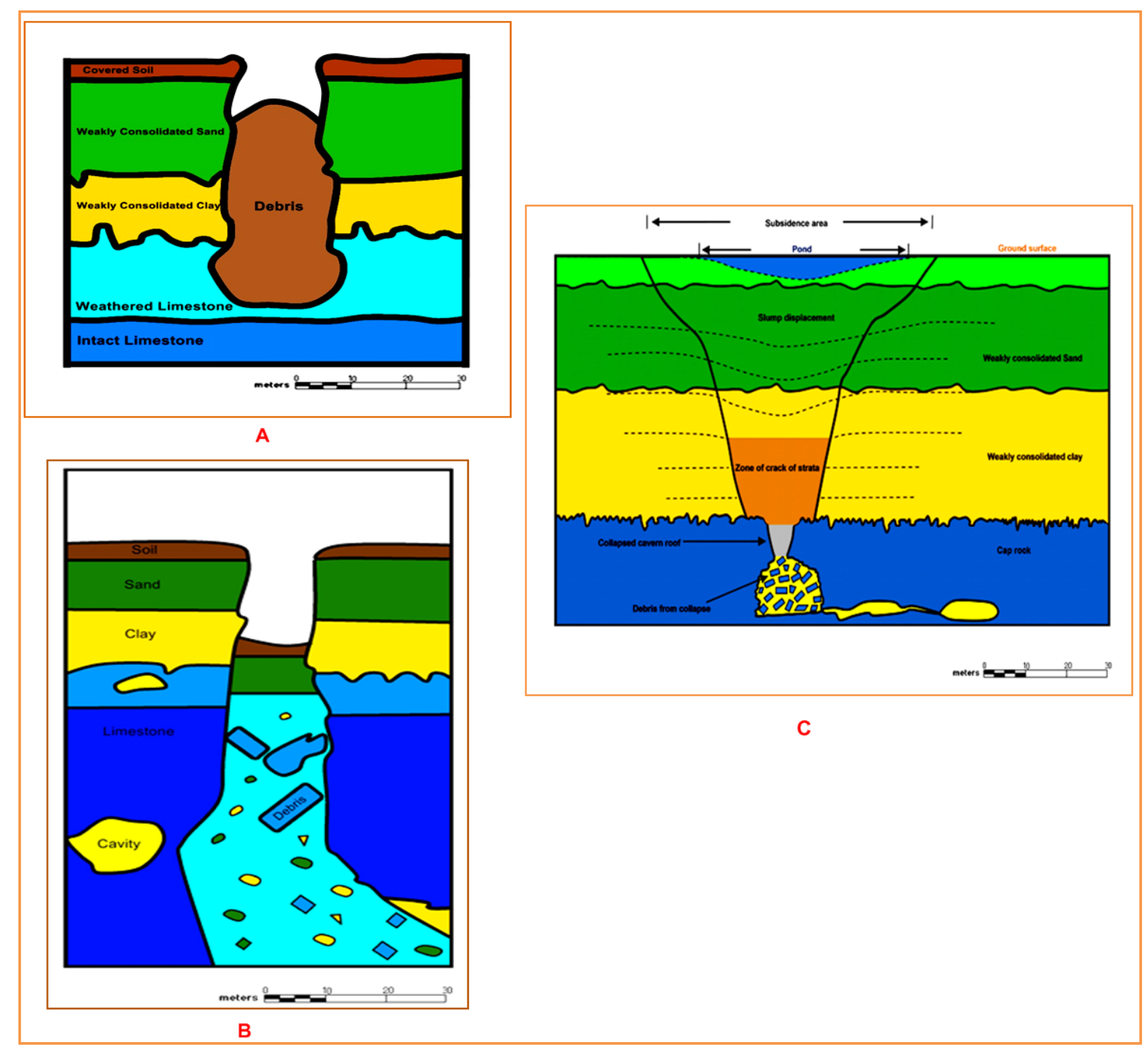

Figure 14(A-C). Diagrammatic cross-sections illustrating the type of sinkholes in the study area, A: The soil cover- collapse sinkhole was within overlain cover soil as a result of a thick section of weakly unconsolidated sand and clay. B: The cover layer - subsidence sinkhole as a result of a bridge collapses and thick section of clay. C: the cavern roof collapse within the cap rock that is overlain by a thick section of unconsolidated or weakly compacted sands and mudstones 
The second kind of sinkholes, depending upon the size of the cavity, is referred to as cover layers- subsidence sinkholes. Occasionally, if the sediments were more clay-based, the upper cover will lean towards becoming more inclined. This bridge will provide some dependence to the clay above. However, if this bridge collapses, the material acts as a conduit to any vacant cavity in the limestone bedrock. Some of the sinkholes appear due to an essential variance in the behavioral strength of the soil above the cavity, and the fact of whether this subsides slowly or collapses suddenly. The size of the sinkhole depends upon the size of the cavity, and whether or not it spreads efficiently and intersects the water table. The dissolution processes is possibly reduced in order to reduce the perpendicular difference between the phreatic water table and prospective meteoric surface, and consequently, reducing the percolation processes, as illustrated in figure (14-B).

The third kind of sinkholes discovered in the study area is a sinkhole-like slump depression produced at the ground's surface. This kind is distributed in different sizes and diameter from $5 \mathrm{~m}$ to more than $35 \mathrm{~m}$ in the study area. Mostly this kind of sinkholes formed after the Indonesia tsunami in 26 December 2004 in which it cannot be observed in satellite images before 2004. These kinds of sinkholes are present in weak sediments or when unconsolidated layers lie above the limestone cap rock.

The displacement may result in plastic deformation for the space located immediately higher than the collapsed area, depending on the lithology and the amount of water associated with these sediments. Due to the upper strata collapsing on the roof of the cavern, which is part of an extensive cavern, the network itself will collapse. The clay-based sediment shall be transported and deposited a considerable distance away from the cavern via the continuous removal of material entering from the channel or conduit area, allowing the upward development of the conduit, diverting the occurrence of collapse to the surface, as illustrated in figure (14-C).

The fourth type of sinkholes discovered were openings with a funnel shape depression or sink that might develop in the future, generally referred to as piping. This occurs when the rain in-fill is on a slightly impermeable surface layer. During the infiltration process, the water passes through the soil and migrates towards a widened fracture caused by the dissolution process. Water then moisturizes the soil in the area around the opening hole of the conduit or fracture. As a result, the moistened soil begins to lose its cohesive properties, and begins to break apart and falls into the opening drain. The water began to erode the sediment from around these opening and migrate or move down toward the drain, with the sediments under the influence of gravity; it leaves a void or open area in the soil. Around the opening, a funnel-shape depression or sink has the potential to develop in the near future. The downward passage of the conduit or fracture can be enlarged with the passage of time by erosion or dissolution.

For piping to occur, two basic geologic conditions must be met: first, there must be a considerable quantity of materials (sediments or rocks) between the ground surface and the water table; and second, the condition of that sediments or rocks above the water table is capable of maintaining open fractures. Most of the site in the study meets these conditions, as there are high quantities of sediments between the ground surface and the water table. The piping process without the effect of the water table is illustrated in the diagrammatic cross-section in figure (15-A).

The piping processes include infiltration and dissolution, and both can be active along the same fracture system. Although these processes are in hydraulic communication specified by a sufficient time, the two individual processes can be combined to produce a collapsed-pipe sinkhole. The emergence of a sufficient volume of material dissolution processes can take place in widening conduits or fractures in the cap rocks of limestone, which is overlain on the water table. However, if these processes result in fractures below the water table, it could allow meteoric water to penetrate downward along these fractures, and freely mix with phreatic water. The piping process when the water table has been lessened to a lower position below the top of the cap rock of the limestone is illustrated in the diagrammatic cross-section in figure (15-B). 


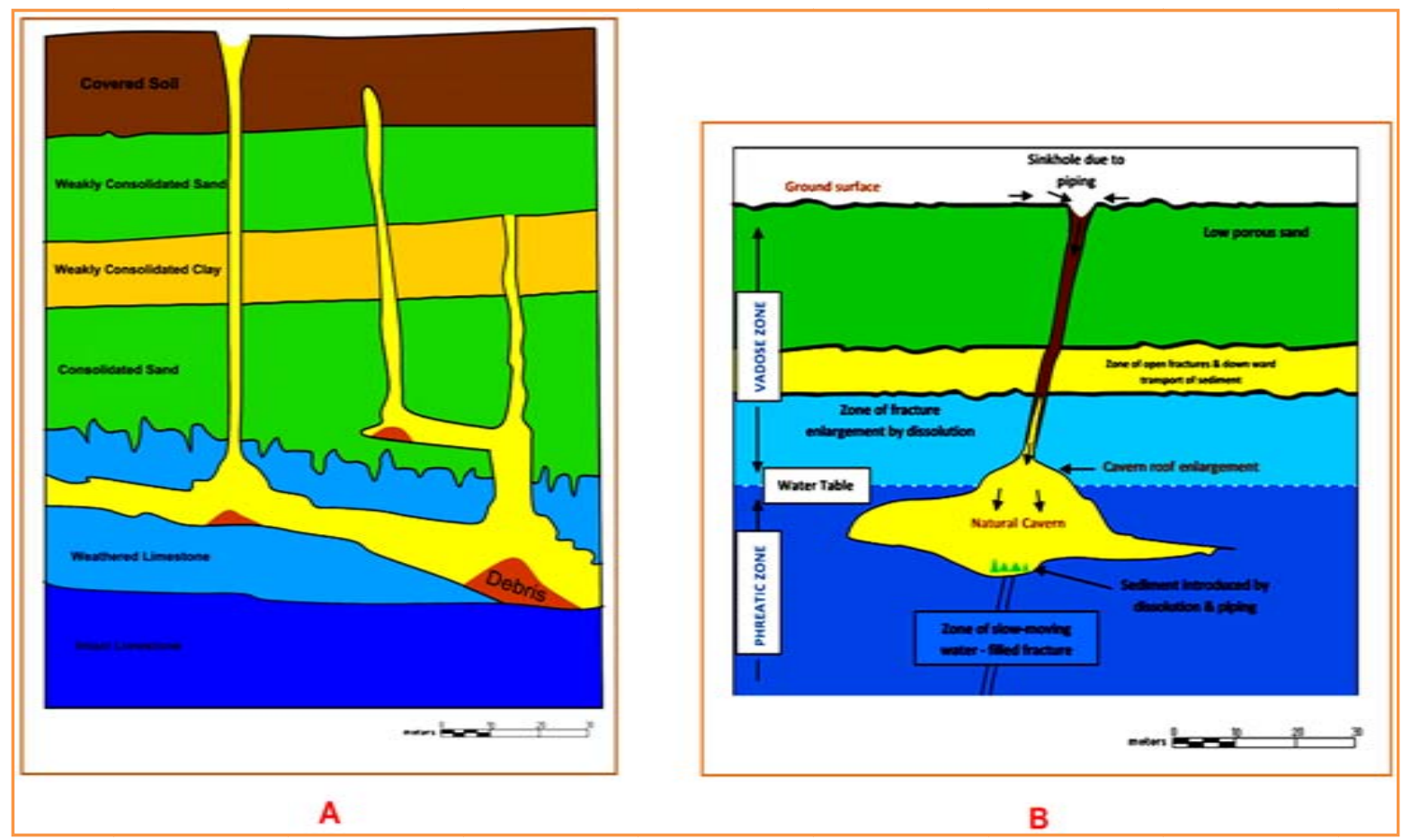

Figure 15(A-B). Diagrammatic cross-sections illustrating the type of piping in the study area, A: the piping process without the effect of water table. B: the piping process when the water table has been lesser to a lower position below the top of the cap rock of the limestone

\section{Depth of Limestone Bedrocks}

The area under study is a division of Kinta Valley's karst topography. Commonly it's in the vicinity of complex ground conditions. It is often insufficiently understood, except by those who are familiar with soluble rock. Limestone causes numerous difficulties, which increases in scale and complexity with the increasing development of karsts' morphology. The depth of the weathered limestone and the depth of intact or sold limestone bedrocks provide an outline, or a description of some of the selected points with regards to the depth of the limestone bedrock in the study area, summarized in table 4 . This will be beneficial in understanding the probable topography conditions of the limestone bedrock. However, this provides a general suggestion of expected ground conditions if there was enormous variation occurring with the depth of limestone bedrock in the limited region.

Table 4. Summarizes the approximate depth of weathered and intact limestone bedrocks in the study area extracted from interpretation of resistivity data

\begin{tabular}{|c|c|c|c|c|c|c|c|}
\hline No. & Profile no. & Electrode no. & \begin{tabular}{|c|}
$\begin{array}{c}\text { Approximate depth } \\
\text { of weathered } \\
\text { Limestone Bedrocks }\end{array}$ \\
\end{tabular} & Electrode no. & \begin{tabular}{|c|}
$\begin{array}{c}\text { Approximate depth } \\
\text { of Intact Limestone } \\
\text { bedrock }\end{array}$ \\
\end{tabular} & Electrode no. & $\begin{array}{c}\text { Approximate depth of } \\
\text { pimnacles }\end{array}$ \\
\hline 1 & Profile no.1 & $\begin{array}{l}14 \\
20 \\
27\end{array}$ & $\begin{array}{l}19 \\
17.5 \\
11\end{array}$ & $\begin{array}{l}14 \\
20 \\
27\end{array}$ & $\begin{array}{c}22 \\
20 \\
13.5\end{array}$ & 27.28 & 10.5 \\
\hline 2 & Profile no.2 & $\begin{array}{l}14 \\
20 \\
27\end{array}$ & $\begin{array}{l}22 \\
16.8 \\
17.8\end{array}$ & $\begin{array}{l}14 \\
20 \\
27\end{array}$ & $\begin{array}{l}25 \\
19.8 \\
20\end{array}$ & $21-22$ & 12 \\
\hline 3 & Profile no.3 & $\begin{array}{l}14 \\
20 \\
27 \\
30\end{array}$ & $\begin{array}{c}21.8 \\
13.5 \\
15.4 \\
11\end{array}$ & $\begin{array}{l}14 \\
20 \\
27 \\
30\end{array}$ & $\begin{array}{c}23 \\
15.7 \\
18.5 \\
16.5\end{array}$ & $\begin{array}{l}18-19 \\
23-24 \\
31-32\end{array}$ & $\begin{array}{l}12.5 \\
14.5 \\
11\end{array}$ \\
\hline 4 & Profile no. 4 & $\begin{array}{l}14 \\
20 \\
27\end{array}$ & $\begin{array}{l}23 \\
21.8 \\
18.5\end{array}$ & $\begin{array}{l}14 \\
20 \\
27\end{array}$ & $\begin{array}{l}26 \\
24 \\
20.5\end{array}$ & $22-23$ & 15.5 \\
\hline 5 & Profile no.5 & $\begin{array}{l}15 \\
20 \\
27\end{array}$ & $\begin{array}{l}21.8 \\
17.4 \\
10\end{array}$ & $\begin{array}{l}15 \\
20 \\
27\end{array}$ & $\begin{array}{c}24 \\
18 \\
19.8\end{array}$ & $21-22$ & - \\
\hline
\end{tabular}


The electrical resistivity data acquired at this site was processed to generate the $2 \mathrm{D}$ resistivity models of the subsurface. Ten boreholes were opened, with a maximum depth of $12 \mathrm{~m}$. The borings are completed in the unconsolidated material of soil, clay, sandy clay and sand over karstified limestone. This boring was used to define the limestone/clay boundary and a few of the sinkholes spatially. The depth of the boreholes was approximately ranging from $3,6,9,10$ to $12 \mathrm{~m}$. The depth of the boreholes to bedrock was defined as the depth that refuses auguring in the borings. The mistake found in the boring data is the result of the borings recording the top of the weathered limestone zone, instead of the top of the intact or unweathered limestone bedrock. A number of borings have been stopped by residual boulders in the overburdened region, or by limestone fragments.

The limestone dipped approximately toward the southwest in this site. When comparing the interpretations from individual profiles with the boring data, it was discovered that more of the data points have fewer errors of less than $1 \mathrm{~m}$, and some of the data points have errors of less than $3 \mathrm{~m}$. When the boring penetrate deeper in order to reach one of the limestone pinnacles beneath electrode no. 27 in profile no.1, the auger became very problematic in the borings when it reaches a depth of $9 \mathrm{~m}$, which represent the transitional zone that contains limestone rock fragments and sand.

\section{The Effect of Alteration in the Environment on the Future of Land Use in This Karst Region}

The alterations in Karst Region's environment occur on both the surface and subsurface. The actions that are responsible for these alterations are possibly direct or indirect in nature. The variation in karst environments may maneuver the karst situation toward or away from its boundaries Williams, P.W. (1993).

There is an urgent need for a better understanding of the association between primary actions that impact the karst situation in both, short- or long-term periods, such as agriculture, irrigation and mining, on top of soil erosion and its movement, the rates of sedimentation, and groundwater contamination. The presence of underlying fissures and joints is likely to facilitate the migration of soils from the surface. These features can deepen and disturb the surface of the soil. Sources of contamination include fertilizers and manure disbursed to fields for crop production. The failure to supervise areas and unfortunate management in storing the manure and fertilizers, and the application of liquid fertilizers using irrigation techniques may increase the erosion of the surface's soil. In addition, the inappropriate tillage techniques, such as before heavy rainfall may facilitate the emergence of sinking streams, cavity and sinkholes. This can cause rapid subsurface runoff, and likely lead to increased sediment loads due to erosion in the subsurface emergent streams. Leaving a crop residue cover on the soil surface can increase infiltration, and cause the loss of soluble nutrients to groundwater. This study found that this area and other areas with similar specifications is hazardous for constructing accommodation for habitation, or creating animal sheds by farmers, as well as manure storage facilities, feed storage, and poultry production. There is a possibility of collapse or subsidence of the soil cover or material, or its underlying layers due to the load at any time in the future. This study also identified the presence of an area undergoing subsurface erosion that may eventually collapse in future.

\section{Results and Discussion}

This paper demonstrates that ERT is a useful geophysical tool that is appropriate for imaging the bedrock and overburden layers to determine the subsurface karst features in covered karst terrains. The electrical resistivity data acquired from the survey is constructive for several reasons:

\subsection{Geophysically}

a. The complete data analysis and suitable design of profiles arrangement are important factors ensuring the achievement of the project objectives. Karstic features can be delineated by completed closely spaced parallel resistivity profiles and imaging the subsurface immediately across and in-proximity to many sinkholes, in order to determine the karstic features such as (sinkholes, voids and cavities).

b. It provided dependable images and supported the interpretation that the study area is underlain by several varieties of karsts features (sinkholes, cavities and voids).

c. It can be useful for characterizing the subsurface bedrock in covered karst terrains. In this study, it is recognized that the subsurface limestone bedrock was widely karstified and provided dependable images of the karstified limestone bedrock.

d. It identified the type of sediments in the subsurface layer, including estimation for its approximate depth and thickness.

e. It indicated that the surface was overlain in various places by friable sand and remnant of limestone rock 
and other rock fragments due to high resistivity recorded in most of the overburden cover.

\subsection{Geologically}

a. Several varieties of sinkholes with different origins were discovered in the study area through the information, geological and geophysical survey data records. The first types of sinkholes discovered were a few meters in diameter and depth, referred to as cover-layers or material subsidence. The second type was wider than the first type in terms of diameter and depth, and is referred to as cover-collapse sinkholes. The third type of sinkhole resembles a slump depression produced on the ground surface, and the fourth type is an opening with a funnel-shape depression or sinks, which is referred to as pipes.

b. Many empty (air-infill) sinkholes were found at this site, which supports the assumption that the emptying or infilling of these sinkholes was the foundation of the stripping of the portion of the topsoil and granules of sand that drops down (in almost all of the study area). This is likely due to the fact that there are heavy runoff rains in the study area. Also, there is a difference in the topography of the exposed rock, or because of the subsidence movement in the area. The result is the channeling of materials towards the sinkhole in order to fill the void in the layer beneath, or to fill the cavity through an existing joint/fracture in limestone bedrock. These sinkholes measure only a few feet in diameter and depth, respectively. Their small size is due to the fact that the cavities in the limestone cannot develop to considerable sizes before they are in-filled with sand. Several small sinkholes empty and sand in-fills were identified during the site ground work inspection presented in Figure 16.

c. The overlying sand found in many places on the surface in the area of study, is mostly characterized by high resistivity; interpreted as sand dry and friable with remnants of limestone rock or other rock fragments, had been stripped by earth-moving equipment from the pits of mine, due to ex-mining excavating operation.

d. Through sinkhole observation, standing water remained or stayed in the sinkhole days after the feature formed, suggesting that the flush or the migrates were stopped. This occurs when the conduit or the pipe that was formed due to solution-widened joints becomes choked or blocked with clay or other material to these drainage, because the size of the cavities in the limestone bedrock are in-filled or loaded with clay-base and sandy material. Otherwise, in the rainy season, the meteoric water flushing down through the sinkhole will cause the water table to increase, if the sinkhole spreads laterally and intersects the water table. The dissolution is reduced because there is less vertical difference between the water table and meteoric water surface and here, the flush or migrates will be less.

e. The geological model interpreted from the geophysical data consists of a basal limestone unit, which constitutes the bedrock of the study area, the overburdened layers consisting of sand, containing lenses of clay and covered by soil or sandy clay and friable sand and rock fragment in certain places. Intervened by sinkholes and cavities filled with clay or sandy clay and sand; it is interpreted as a karstic processes.

f. ERT provides a sufficient resolution to pinpoint the locations of filled sinkholes and other geophysical anomalies, and identified an area of ongoing subsurface erosion that may eventually collapse in the near future. A potential collapse may be due to the presence of longitudinal anomalies in the shape of lenses or cavities in-filled with meteoric water and thick clay. Other materials of sandy or silty clay might also collapse when subjected to a piping under load, and threaten the site in the future.

g. Sinkholes in many different shapes and sizes were recognized in the study area. They are generally circular in outline, conforms to similar shapes such as elliptical or irregular configuration, or look like a funnel. A tunnel or throat is visible within the hole, representing a soil pipe that leads to the bedrock drain.

h. The group includes 10 small sinkholes found in the study area, representing the daughters, while the big sinkhole represents the mother. Due to the interconnected nature of the karst features system, this group of small sinkholes can also bond to form a larger sinkhole, with its shape changing over time, from steep to nearly vertical sidewalls. The portions of the sidewalls can break off over time and fall into the sinkhole. As this process continues, the sinkhole gets larger. If water continues to be added into the sinkhole, it can also get deeper.

i. In accordance to classification of karstic ground conditions dependent on the morphological features characterisation by Waltham, A.C., \& Fookes PG (2003), the karst level found in the study area ranges between mature karst KIII to complex KIV. 


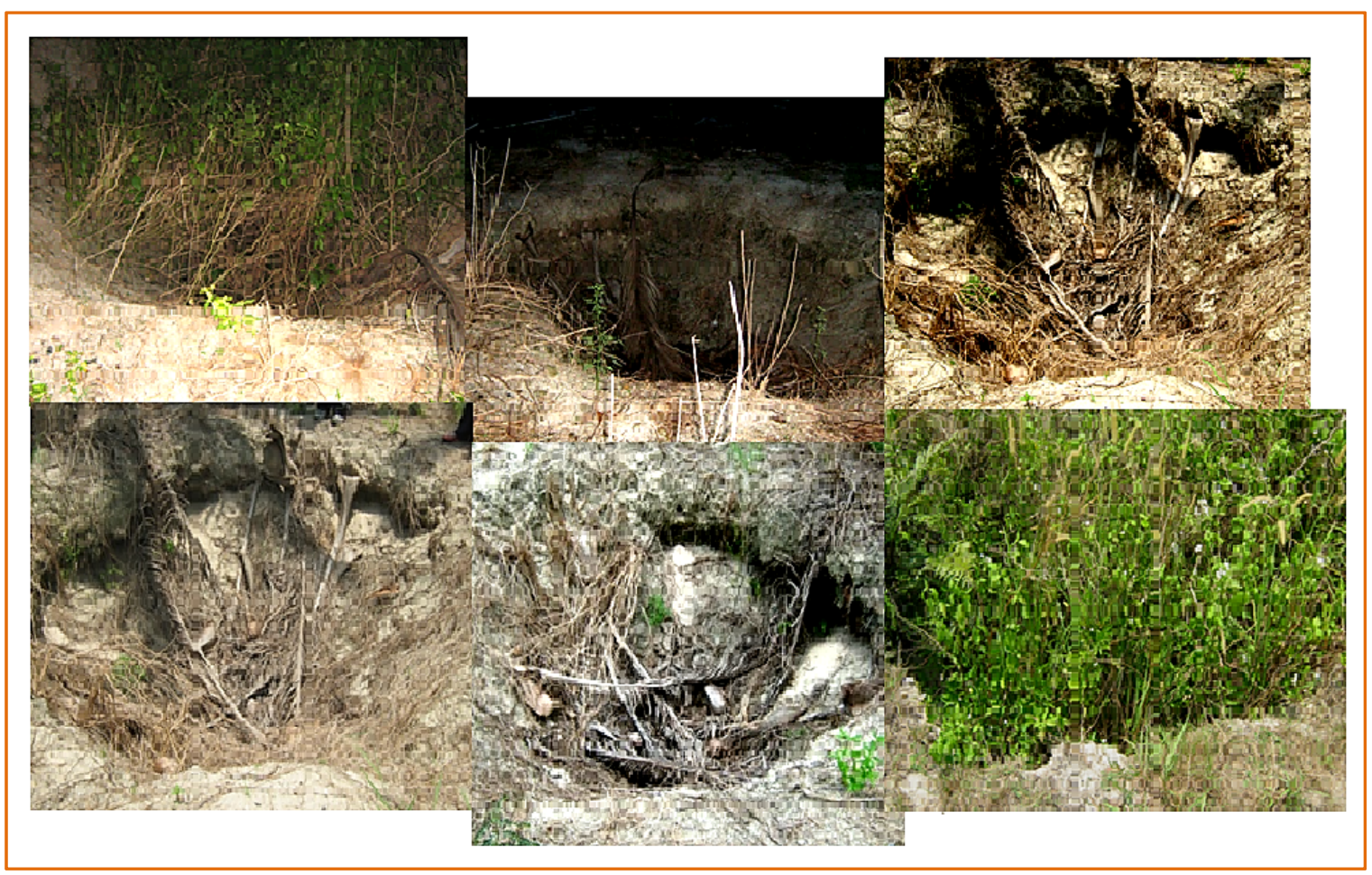

Figure 16. Several of small sinkholes describe as empty, sand in-fills and crammed with vegetations were identified during the site ground work inspection

\section{Recommendation}

This paper focuses on the usefulness of ERT as a geophysical tool to capture the images of the bedrock and overburdened layers in order to determine the subsurface karst features located in selected area, situated in Kinta Valley, named Kampong Kunsila estate, in the northwest of Kampar and south of Ipoh, the capital of Perak, Peninsula Malaysia. In this study of covered carbonate karsts terrain, several varieties of sinkholes were discovered through the information and data record of geological and geophysical surveys; and there are more than a few speculated origins for these sinkholes, which are assumed to be due to cover-layers or material subsidence, or due to a cover-collapse sinkholes, or due to a sinkhole-like slump depression, or piping. Also, an ERT with a, 5-m electrode spacing provides sufficient resolution to pinpoint the locations of filled sinkholes and other geophysical anomalies. The ERT identified an area of ongoing subsurface erosion, which may eventually collapse in the near future due to the presence of longitudinal anomalies in shape of lenses or cavities in-filled with meteoric water. These sinkholes contain thick clay and others materials consisting of sandy or silty clay that could collapse when subjected to piping under load, creating a latent site threat in this case in the near future.

The failure to supervise areas and unfortunate management in storage of manure and fertilizers, and the application of liquid fertilizers via irrigation techniques may increase surface soil erosion. In addition, the inappropriate tillage techniques, such as before heavy rainfall may facilitate the emergence of sinking streams, cavities and sinkholes. This study discovered that this area was hazardous to farmers seeking living spaces, or animal's shades or horses stables over the area. This is due to the fact that a collapse or subsidence for the cover soil or material and underlying layers (due to load) might occur at any time in the near future. This study will enable an understanding that an area with specification approximating to this study area will create future threats. The variety of sinkholes identified and delineated in this site during the geological and geophysical survey is presented in Figure 17. 




Figure 17. Several varieties of sinkholes identified and delineated in the site during the geological and geophysical survey

Two solution methods are recommended to use in the plan to minimize the risk of problem areas in this site. The first solution is small sinkholes remediation by using of Bentonite drilling mud and the rock cutting. In this stage is cleaning the land from the plants and boshes. The second stage, small sinkholes remediation by using Bentonite drilling mud and the rock cutting from the drilling operation as one of the steps of environmental management in oil and gas exploration after the water and other liquids are removed to refill the small sinkholes in this site would be the ideal solution. To fill these small sinkholes, first excavating the holes then filling it with bentonite drilling mud and the rock cutting. After that if possible to spray the filling sinkholes with geopolymer chemical solution to fill the gaps between the rocks fragments. The third stage, the upper most of the sinkhole area was completed with bentonite clay about 4.0/5.0 inches to prevent water seepage from occurring. After that the final layer of the ground surface covers with soil about 6.0/7.0 inches. Surface soil need improvement in this construction site by rolling and compaction processes to increase the stiffness through decreasing the permeability in this site.

The second solution using of the deep grouting technique by injection of geopolymer chemical solution grouts (Urethane) is a form of penetration grouting. It's a cost valuable specialized process that uses chemical solution forms to fill the small voids and fissures in the soil. The granular soils with considerable sand with fine and medium size contents are the best appropriate for this technique. That will strengthen the ground and prevent excessive movement. Chemical grout is injected through the joints and gaps in the surrounding soil and sand, where it solidifies with the soil to making it appear relatively impermeable and hard.

\section{Conclusions}

A combination of Wenner Electrical Resistivity Tomography, geological and satellite imaging techniques was applied to determine the sinkholes and overburdened thickness in the covered carbonate karst terrains for the purpose of studying the Kinta Valley (Kampong Kunsila estate), located in the northwest of Kampar, south of Ipoh, Perak, Peninsula Malaysia; Two Dimensional (2-D) electrical resistivity imaging/tomography surveys was conducted by employing a large number of electrodes using a 41-channel and array in Wenner configuration, 
displayed in five traverses or profiles across and in-proximity to many sinkholes located at the site.

The electrical resistivity data were collected and assumed to identify the origin of these sinkholes and their shapes; on top of estimating a sinkhole's and the bedrock's (limestone) depth. Furthermore, it generates the geological model of the area under study and the type of overburdened sediments and its thickness. Several varieties of sinkholes were discovered in the study area via the information and data record of geological and geophysical survey, more than a few causes of origins were speculated for these sinkholes. This study found that this area and other areas with similar specifications are hazardous for constructing accommodation for habitation, or creating animal sheds, as well as manure storage facilities, feed storage, poultry farms, etc. There is a possibility of collapse or subsidence of the soil cover or material and underlying layers due to the load at any time in the future. This study also identified the presence of an area of ongoing subsurface dissolutional erosion that may eventually collapse in the near future. Two solution methods are recommended to use in the plan to minimize the risk of problem areas in this site.

\section{References}

Anderson, N. L., Apel, D. P., \& Ismail, A. (2007). Assessment of karst activity at highway construction sites using the electrical resistivity method. Missouri, USA.

Austin, S. A., Baumgardner, J. R., Humphreys, D. R., Snelling, A. A., Vardiman, L., \& Wise, K. P. (1994). Catastrophic plate tectonics: a global flood model of earth history. Proceedings of the third international conference on creationism, technical symposium sessions, pp. 609-621.

Baumgardner, J. R. (1990a). Changes accompanying Noah's Flood. Proceedings of the second international conference on creationism, II, 35-45.

Baumgardner, J. R. (1990b). The imperative of non -stationary natural law in relation to Noah's flood. Creation research society, Quarterly, 27(3), 98-100.

Cobbing, E. J., Pitfeld, P. E. J., Derbyshire, D. P. F., \& Mallick, D. I. J. (1992). The granites of Southeast Asian tin belt. Overseas Memoir 10, British Geological Survey of London, pp. 78-86.

Cooper, A. H., Farrant, A. R., \& Price, S. J. (2011). The use of karst geomorphology for planning, hazard avoidance and development in Great Britain. Geomorphology, 134, 118-131. http://dx.doi.org/10.1016/j.geomorph.2011.06.004

Dahlin, T., \& Loke, M. H. (1998). Resolution of 2D Wenner resistivity imaging as assessed by numerical modeling. Journal of Applied Geophysics, 38, 237-249. http://dx.doi.org/10.1016/S0926-9851(97)00030-X

Fontaine, H., \& Bin- Amnan, I. (1995). Biostratigraphy of the Kinta valley, Perak. Geological society. Malaysian Bulletin, 38, 159-172.

Griffiths, D. H., \& Barker, R. D. (1993). Two-dimensional resistivity imaging and modeling in areas of complex geology. Journal of Applied Geophysics, 29, 211-226. http://dx.doi.org/10.1016/0926-9851(93)90005-J

Hutchinson, C. S. (2007). Geological evolution of Southeast Asia. (2nd edition), Geological Society of Malaysia (Publ), p.433.

Ingham, F. T., \& Bradford, E. P. (1960) .The geology and mineral resources of the Kinta valley, Perak. Geological Survey District Memoir 9, Federation of Malaya Geological Survey, Ipoh, 347.

Li-Guang, S. Z., \& Qing, X. (2008). Hot Cradle of El Niño, Institute of Polar Environment. School of Earth and Space Sciences, University of Science and Technology of China, Hefei, Anhui, 230026, P R China.

Loke, M. H., \& Barker, R. D. (1994) .Rapid least-squares inversion of apparent resistivity pseudosection using a quasi-Newton method., Extended Abstracts of Papers 56th EAGE Meeting Vienna, Austria 6-10 June 1994, p. 1002.

Louis, I. F., Louis, F. I., \& Bastou, M. (2002). Accurate Subsurface Characterization For Highway Applications Using Resistivity Inversion Methods. Geophysics \& Geothermic Division, Geology Department, University of Athens, Panepistimiopolis, Ilissia, Athens.

Muhammad, R. F. (2003). The characteristic and origin of the tropical Limestone Karst of sungai Perak basin, Malaysia. Unpubl. PhD, University of Malaya, 443.

Muhammad, R. F., \& Yeap, E. B. (2002). Estimate the dissolution rates in Kinta and Lenggong valleys by using of the micro erosion meter. Geological Society Bull: 45, pp.26-27.

Muhammad, R. F., Al-Kouri, O., \& Yassin, R. R. (2010). Geophysical and geospatial database of sinkhole 
occurrences distribution after earthquake tsunami, Department of Geology, Faculty of Science, University of Malaya.

Sathiamurthy, E., \& Voris, H. K. (2006). Maps of Holocene sea level transgression and submerged lakes on the Sunda shelf. Journal of Chulalongkorn University, Supplement, 2, 1-44.

Sowers, G. F. (1996). Building on sinkholes. American society of Civil engineers, New York.

Telford, W. M., Geldart, L. P., \& Sheriff, R. E. (1990). Applied Geophysics. (2nd add), Cambridge University Press, New York. http://dx.doi.org/10.1017/CBO9781139167932

Walker, D. A. (1999). First Tsunami Symposium Papers - II. The international journal of the Tsunami society, $17(2)$.

Waltham, A. C., \& Fookes, P. G. (2003). Engineering classification of karst ground conditions. Quarterly Journal of Engineering Geology and Hydrogeology, 36, 101-118. http://dx.doi.org/10.1144/1470-9236/2002-33

Williams, P. W. (1993). Environmental change and human impact on karst terrains: An introduction. In Williams PW (Ed.) Karst Terrains, environmental changes, human impact. Catena Supplement, 25, 1-19.58 Urich Land use in karst terrain.

Yahia, N. A., Yassin, R. R., \& Abdel- Qadir, S. O. (1992). The results of applying geophysical techniques in prospecting and investigation of bauxite ore deposits in subsurface karst terrains / Iraqi western desert. Paper no.2262, geosurv, Baghdad - Iraq.

Yassin, R. R. (2002). Evaluate the presence of Bauxitic clays in selected sites on carbonate karst regions in western desert of Iraq by application of Vlf - electromagnetic and electrical resistivity techniques. Department of geology, College of science, University of Baghdad. / Baghdad - Iraq, p. 223.

Zhou, W., Beck, B. F., \& Stephenson, J. B. (2000). Reliability of dipole-dipole electrical resistivity tomography for defining depth to bedrock in covered karst terrains. Journal of Environment Geology, 39(7), 760-766. http://dx.doi.org/10.1007/s002540050491

\section{Copyrights}

Copyright for this article is retained by the author(s), with first publication rights granted to the journal.

This is an open-access article distributed under the terms and conditions of the Creative Commons Attribution license (http://creativecommons.org/licenses/by/3.0/). 